\title{
Comparative Skull Osteology of Karsenia koreana (Amphibia, Caudata, Plethodontidae)
}

\begin{tabular}{|r|l|}
\hline Journal: & Journal of Morphology \\
\hline Manuscript ID: & JMOR-09-0172.R1 \\
\hline Wiley - Manuscript type: & Research Article \\
\hline Date Submitted by the \\
Author: & \\
\hline Complete List of Authors: & $\begin{array}{l}\text { Buckley, David; Univ of California, Integrative Biology \& Museum } \\
\text { Vertebrate Zoology } \\
\text { Wake, Marvalee; Univ of California, Integrative Biology } \\
\text { Wake, David; Univ of California, Integrative Biology \& Museum of } \\
\text { Vertebrate Zoology }\end{array}$ \\
\hline Keywords: & $\begin{array}{l}\text { evolution, morphology, bones, lungless salamanders, hyobranchial } \\
\text { apparatus }\end{array}$ \\
\hline &
\end{tabular}

\section{scholarONE \\ Manuscript Central}


Comparative Skull Osteology of Karsenia koreana (Amphibia, Caudata, Plethodontidae)

2

3 David Buckley*, Marvalee H. Wake and David B. Wake

4 Department of Integrative Biology \& Museum of Vertebrate Zoology, 3060 Valley Life

5 Science Building, University of California, Berkeley, CA 94720-3140, USA.

6

7 *author for correspondence:

8 David Buckley

9 Department of Integrative Biology \& Museum of Vertebrate Zoology, 3060 Valley Life

10 Science Building, University of California, Berkeley, CA 94720-3140, USA

11 Phone: 510- 6439472

12 Fax: 510- 6436462

13 e-mail: dbuckley@berkeley.edu

14

15 Running title: Karsenia koreana skull osteology

16 The manuscript contains 61 pages and 10 figures.

17

18

19

20 


\section{ABSTRACT}

22 The recent discovery of a plethodontid salamander, Karsenia koreana, in Korea challenged

23 our understanding of the biogeographic history of the family Plethodontidae, by far the

24 largest family of salamanders, which otherwise is distributed in the New World with a few

25 European species. Molecular studies suggest that Karsenia forms a clade with Hydromantes

26 (sensu lato), which includes among its species the only other Old World plethodontids. We

27 studied the skull of $K$. koreana and compared it to that of other plethodontid genera,

28 especially members of the subfamily Plethodontinae, which it resembles most closely in

29 general anatomy. The anatomy of its skull corresponds to the most generalized and

30 apparently ancestral condition for plethodontids. No clearly autapomorphic states were

31 detected, and no synapomorphies can be found that would link it to other genera. The

32 Karsenia skull is cylindrical and well ossified, giving an impression of strength. In

33 contrast, the skull of Hydromantes is highly derived; the skull is flattened and the bones are

34 weakly ossified and articulated. Hydromantes and Karsenia share no unique anatomical

35 features; differences between them are especially evident in the hyobranchial skeleton,

36 which is generalized in Karsenia but highly modified in Hydromantes, which is well-

37 known for its highly projectile tongue. Plethodon and Plethodon-like species, including

38 Karsenia and to a lesser degree Ensatina, represent the more generalized and apparently

39 ancestral plethodontid morphology. Specialized morphologies have evolved along only a

40 few morphological axes within the Plethodontidae, resulting in a pattern of rampant

41 homoplasy. Our analysis of the anatomy of the new Asiatic lineage illuminates some

42 potential mechanisms underlying adaptive morphological evolution within the

43 Plethodontidae.

44

45 Key words: evolution, morphology, bones, lungless salamanders, hyobranchial apparatus. 
47

48

49

50

51

52

53

54

55

56

57

58

59

60

61

62

63

64

65

66

67

69

68 Eurycea, Gyrinophilus, Pseudotriton, Stereochilus, and Urspelerpes), and the genus

\section{INTRODUCTION}

The order Caudata comprises 583 species of salamanders (AmphibiaWeb, September 2009. http://amphibiaweb.org/index.html). The family Plethodontidae, with 394 species, is the most diverse family, both in number of species and in ecological and morphological variability. Plethodontid salamanders occupy a vast array of ecological niches, adapting to very different habitats (e.g., aquatic, fossorial, arboreal, stream, terrestrial or cave; Wake, 1966). Most plethodontids lay eggs on land, which develop directly into miniatures of the adults without an intervening larval stage. Species with the basal amphibian biphasic life cycle, as well as paedomorphic (permanently larval) forms, also occur, but at least in the Plethodontinae the larvae are secondarily derived (e.g., species of Desmognathus;

Chippindale et al., 2004; Mueller et al., 2004). Despite morphological variability related to the ecological diversification of the group, synapomorphic traits characterize the family, such as the absence in adults of lungs, pterygoid and lacrimal bones, and the presence of a naso-labial groove and large posterior patches of vomerine teeth (Wake, 1966).

Several principal evolutionary lineages are recognized within the family, arrayed taxonomically in different groups depending on the authors (e.g., Wake, 1966; Lombard and Wake, 1986; Chippindale et al., 2004; Mueller et al., 2004; Frost et al., 2006; Vieites et al., 2007). The most recent revision of the group recognized two subfamilies within Plethodontidae: (i) Hemidactyliinae, which includes the supergenus Bolitoglossa (12 genera; > 250 species of tropical salamanders), the western North American genus Batrachoseps (20 species), the tribe Spelerpini (Eastern North American species, genera

9 Hemidactylium (monotypic genus), the last a distinct lineage whose taxonomic position has 
70 been rather controversial; (ii) Plethodontinae, which includes the supergenus

71 Desmognathus (genera Desmognathus and Phaeognathus), the North American genera

72 Aneides, Ensatina, and Plethodon, the supergenus Hydromantes (genera Atylodes,

73 Hydromantes, and Speleomantes), and the recently described genus Karsenia (Vieites et al., 74 2007).

75 Karsenia is a monotypic genus that contains the only known Asiatic plethodontid,

76 Karsenia koreana, recorded from only a few localities in South Korea, where individuals

77 can be found under rocks on the humid slopes of montane woodlands with limestone soils

78 (hardwoods and mixed hardwood/pine; Min et al., 2005). The species has the characteristic

79 features of plethodontid salamanders (the absence of lungs, pterygoid and lacrimal bones in

80 adults, and the presence of a naso-labial groove and large posterior patches of vomerine

81 teeth). The first molecular analyses carried out confirmed the singularity of the new lineage

82 (Min et al., 2005). This, together with some morphological particularities such as an

83 attached protrusible tongue and a derived tarsus, as well as its geographic distribution, led

84 to the description of a new genus for the species (Min et al., 2005). A thorough molecular

85 study confirmed the inclusion of $K$. koreana within the plethodontine salamanders (Vieites

86 et al., 2007). In that phylogenetic analysis, Karsenia forms a clade with the species from

87 the supergenus Hydromantes, the clade being sister to the remaining plethodontines (Fig.

88 1). Furthermore, $K$. koreana shares synapomorphic karyological characteristics with

89 Hydromantes (Sessions et al., 2008).

90 Plethodontid salamanders are distributed primarily in the New World (99\% of species).

91 Most of the species are found in North and Middle America, with the exception of the eight

92 that occur in the Mediterranean region. Several hypotheses have been proposed to explain 
93 the current geographic distribution and the patterns of diversification in Plethodontidae

94 (e.g., Wilder and Dunn, 1920; Wake, 1966; Wake, 1987). However, these evolutionary and

95 biogeographic scenarios were challenged by the discovery of the Asian species Karsenia

96 koreana (Min et al., 2005; Vieites et al., 2007). This discovery has led to an acceptance of a

97 postulated early connection across the Bering Strait between species in western North

98 America and their relatives in western Europe.

99 In addition to its relevance for recovering the biogeographic history of the family, $K$.

100 koreana may also play an important role in understanding the patterns of morphological

101 evolution and ecological diversification within the group. Plethodontid salamanders are the

102 most speciose and diversified group of salamanders, but the diversity and disparity of forms

103 are unevenly distributed within the family (Wake, 1966). Levels of specialization and

104 speciation are not directly correlated, and highly specialized and generalist forms coexist

105 within the different plethodontid lineages. The general morphology of the group is highly

106 conserved, and the specialized forms have diversified along a few similar morphological

107 axes (Wake and Larson, 1987; Wake, 1991). Recurrent evolution of similar morphological

108 traits across lineages, i.e. homoplasy, is a common theme among the Plethodontidae (Wake, 109 1991).

110 Given the singularity and importance of the new lineage, we describe the osteology of

111 the skull of $K$. koreana. We compare the results with the characteristics of other members

112 of the Plethodontinae (Hydromantes, Aneides, Ensatina, Plethodon, Desmognathus and

113 Phaeognathus). Superficially, Karsenia resembles members of Plethodon, as well as

114 female Aneides hardii, and such members of Desmognathus as D. ochrophaeus and

115 relatives, but we focus especially on Hydromantes because of its putative close 
116 phylogenetic relationship and its hypothetically shared biogeographic history. So far, little

117 is known about the natural history, biology, morphological variability and anatomical

118 characteristics of $K$. koreana, so a detailed and comparative anatomical description may

119 shed some light on the biology and evolution of the species. We also discuss the results in

120 terms of the morphological variability, biology, and evolution of plethodontid salamanders

121 in the framework of the molecule-based phylogenetic hypotheses recently proposed.

122

123 MATERIAL AND METHODS

124 Descriptions are based on High Resolution X-ray CT (HRXCT) scans of Karsenia

125 koreana (DRV 5033, 50.0 snout-vent length [SVL] mm, female, Sanan-Ri, South Korea)

126 and Hydromantes platycephalus (SMR 271, 67.2 mm SVL, male, Inyo creek, Inyo County,

127 California, USA) performed at the High-Resolution X-ray CT Facility at The University of

128 Texas (Austin). The specimen of $K$. koreana was scanned under the following conditions.

129 A FeinFocus microfocal X-ray source operating at $180 \mathrm{kV}, 0.13 \mathrm{~mA}$, and with no filter was

130 used. The source-to-object distance was $39 \mathrm{~mm}$. For each slice, 1400 views were taken,

131 with 4 samples per view. The field of image reconstruction was $9 \mathrm{~mm}$, with an offset of

1326500 and a reconstruction scale of 4600 . The final dataset consisted of 675 slices gathered

133 at a resolution of $1024 \times 1024$ pixels, with an inplane resolution of $9 \mu \mathrm{m}$ per pixel. For the

134 H. platycephalus specimen, the scanning conditions were as follows. The FeinFocus

135 microfocal X-ray source operated at $200 \mathrm{kV}, 0.15 \mathrm{~mA}$, and with no filter. The source-to-

136 object distance was $55 \mathrm{~mm}$. For each slice, 1800 views were taken, with 3 samples per

137 view. The field of image reconstruction was $16 \mathrm{~mm}$, with an offset of 4100 and a

138 reconstruction scale of 4500 . The final dataset consisted of 559 slices gathered at a 
139 resolution of $1024 \times 1024$ pixels, with an inplane resolution of $15.625 \mu \mathrm{m}$ per pixel. The

140 descriptions of the specimens scanned were supplemented by the study of 6 cleared and

141 bone-and-cartilage-stained K. koreana (DRV 5019, 5029, 5551, 5553, 5555, 5558, Jangtae

142 San and Sanan-Ri, South Korea) and two H. platycephalus (MVZ 197502, 197506,

143 Tuolumne County, California, USA). We compared the scanned specimens closely with the

144 cleared individuals and, unless explicitly noted, the cleared specimens have the same

145 morphology as reported for the scanned specimen. Data on ontogenetic or population

146 variability of the structures described cannot yet be provided. All the specimens studied are

147 or will be deposited in the Herpetological Collection of the Museum of Vertebrate Zoology

148 (MVZ), U. C. Berkeley, and in the Herpetological Collection of Southern Illinois

149 University (SIUC).

150 We present detailed descriptions and comparisons between Karsenia and

151 Hydromantes, and we contrast the skulls of these genera with those of the remaining

152 plethodontines. The taxonomy of the Hydromantes group is unstable, and Hydromantes has

153 been considered by different authors as a supergenus containing the genera Hydromantes,

154 Speleomantes and Atylodes (Vieites et al., 2007) and as a genus containing three subgenera

155 (e.g., Wake et al., 2005; van der Meijden et al., 2009), but an equally acceptable taxonomy

156 is to recognize two genera, Hydromantes and Speleomantes, the latter containing two

157 subgenera (Speleomantes and Atylodes) (Crochet, 2007). The results presented here are

158 neutral with respect to taxonomy, and we find it most convenient to refer to Hydromantes

159 (sensu lato) as a clade containing American species (Hydromantes in a restricted sense) and

160 European taxa (Speleomantes and Atylodes). For comparison with other plethodontines

161 (Aneides, Desmognathus, Ensatina, Phaeognathus, and Plethodon), we use the published 
162 comparative osteological descriptions by Wake $(1963,1966)$, in addition to studies of

163 individual genera: Aneides (Wake et al., 1983), Hydromantes (Wiedersheim, 1875; Adams,

164 1942; Hilton, 1945; Lanza et al., 1995), Desmognathus (Means, 1974). We refer to

165 Phaeognathus and Desmognathus collectively as desmognathines. We made new

166 observations of plethodontine taxa using the cleared and stained specimens from the

167 collections of the Museum of Vertebrate Zoology, and we studied on-line CT scans of

168 Aneides lugubris and Phaeognathus hubrichti (http://digimorph.org/). All comparative

169 statements refer to the focal taxon in relation to Karsenia. For the description of the

170 anatomy, we follow the anatomical nomenclature suggested on the Amphibian Anatomical

171 Ontology web site (www.amphibanat.org, June 2009; Leopold et al., 2007; Maglia et al.,

172 2007), based largely on Francis (1934).

173 Segmentation of the individual elements of the skull was performed by tracing the

174 sutures in the original scans, and then reconstructing the images in three dimensions using

175 VGStudio MAX® 1.2 (Volume Graphics, Heidelberg, Germany). Right-side elements were

176 segmented for paired structures. Measurements of structures and angles were taken with the

177 software ImageJ 1.4.1 (Rasband, 2008). Contrast and brightness of the pictures were

178 modified in Adobe Photoshop ® 7.0 (San José, CA).

179 All reconstructions and labeled images will be available on the DigiMorph website

180 (http://digimorph.org/). HRXCT scans of Aneides lugubris and Phaeognathus hubrichti are 181 also available on the website.

182

183 RESULTS 
184

\section{5}

186

\section{7}

188

\section{9}

190

The skull of Karsenia koreana is oval in shape, robust, and well ossified. The skull is fully articulated and scantly ornamented (Fig. 2). Longitudinally, the skull measures 8.1 $\mathrm{mm}$ from the anteriormost tips of the premaxillae to the posterior ends of the occipital condyles. The maximum height is $3 \mathrm{~mm}$ (dorsomedial articulation of frontal and parietal to the transverse plane defined by the ventral surfaces of the dentary), and the widest transverse expanse of the skull is $6 \mathrm{~mm}$ at the level of the anterior ends of the coronoid processes of the prearticulars.

The skull is divided into three areas for descriptive purposes. First, the olfactory capsules and investing bones, forming the facial area, palate and upper jaws, represent one fourth of the total length of the skull. The face is broadly rounded and it rises abruptly in the lateral plane, being slightly rounded anteriorly; the robust alary processes of the premaxillae, which rise almost perpendicularly, are responsible for the slight curvature. The curvature is more pronounced in the transverse plane, and is defined by the lateral surfaces of the nasals and the pars facialis of the maxillae, which are oriented ventrolaterally at a $60^{\circ}$ angle (Fig. 2C,E). The second region, comprising large orbits and the anterior braincase with its investing bones, occupies one half of the skull and is defined by the frontals, the parietals, the parasphenoid, and the orbitosphenoids. The frontals and parietals cover the dorsal braincase and are more or less parallel with the ventral parasphenoid, and the lateral surfaces of the braincase are formed by the orbitosphenoids (which articulate dorsally with the frontals and parietals and ventrally with the parasphenoid; Fig. 2C). The otic capsules and the occipital complex represent the third area and the remaining one fourth of the skull. The otic capsules are rounded and not very prominent. They do not reach the level of the dorsal frontal-parietal surface in height. The squamosals project anteroventrally from the 
207 otic capsules toward the articulars, forming a $45^{\circ}$ angle with the midline of the skull in the 208 dorsal plane and a $33^{\circ}$ angle with the mid-sagittal plane. Finally, the mandible is relatively

209 stout and planar, incorporating dentaries and prearticulars.

210 In comparison to Karsenia, the skull of Hydromantes platycephalus is less well

211 ossified and more loosely articulated. Proportionally, the skull is wider, flatter and less

212 robust (Fig. 2); it is almost spherical in frontal section (Fig. 2B) and compressed

213 dorsoventrally. Longitudinally, the skull measures $12 \mathrm{~mm}$ from the anteriormost tips of the

214 premaxillae to the posterior ends of the occipital condyles. The maximum height is $4.5 \mathrm{~mm}$

215 (dorsomedial articulation of frontal and parietal to the transverse plane defined by the

216 ventral surfaces of the dentary), and the widest transverse expanse of the skull is $11 \mathrm{~mm}$ at

217 the level of the posterior ends of the maxillae. The nasal capsules are poorly ossified and

218 less robust. The alary processes of the premaxillae project vertically and slightly anteriorly

219 in the lateral plane, so the curvature is minimal. The anterior braincase region is more

220 compressed, especially anteriorly, and the investing bones are less planar. The

221 orbitosphenoids increase in height anteroposteriorly. The orbital vacuity is proportionally

222 larger and wider. The otic-occipital area is the most robust part of the skull. The otic

223 capsules are proportionally higher, more prominent and better ossified. Given the wider

224 mandibular arch, the squamosals project toward the articulars with a different inclination,

225 forming a $61^{\circ}$ angle with the midline of the skull in the dorsal plane and a $49^{\circ}$ angle in the

226 mid-sagittal plane. The squamosals are spread more laterally in the dorsal plane and less

227 vertically in the transverse plane. The mandibular arch is oriented ventrodorsally in the

228 lateral plane $\left(10^{\circ}\right.$ angle $)$. 
Premaxillae: Premaxillae are paired structures that are well articulated with each other 230 at the anteriormost end of the skull (Fig. 3A,C). Premaxillae have three distinct regions. 1)

231 The pars dentalis corresponds to the toothed area that forms the anterior end of the 232 maxillary arch. In the specimen scanned, the premaxillary dentition consists of seven teeth 233 on each bone (see Dentition section). The pars dentalis forms a rectangular trapezoid in the 234 transverse plane. The longest edge of the trapezoid corresponds to the toothed area.

235 Medially, the two premaxillae contact squarely, while a slender and toothless projection of 236 the maxilla overlaps the flattened lateral ends. 2) The alary process (pars facialis) projects 237 posterodorsally, first arising vertically as a robust, flattened column, then curving 238 posteriorly and broadening into a flattened wing-like structure that overlaps the facial part 239 of the frontal bone. The alary processes of the two premaxillae define the lateral borders of 240 an oval fontanelle. The flattened portion of the alary process articulates medially with its 241 counterpart, laterally with the nasal, and posteriorly with the frontal. The contact between 242 the posterior ends of the premaxillae and the frontals form an apparent concavity, in which 243 the "nasal gland" is located. 3) The pars palatina consists of a small, flat surface that 244 projects perpendicularly from the longest edge of the pars dentalis to the internal cavity of 245 the cranium. The pars palatina articulates laterally with the lingual edge of the maxilla. The 246 posterior edge of the pars palatina articulates with the anterior margin of the body of the 247 vomer (Fig. 3A,C).

248 In Hydromantes platycephalus, the premaxillae also are paired structures that are not 249 tightly articulated medially with each other (Fig 3B,D). The pars dentalis is more 250 rectangular and proportionally longer than in K. koreana, articulating squarely with its 251 counterpart. The pars palatina is reduced, forming a small irregular shelf, more expanded 
252 at the posteroralteral end. It does not contact the vomer. The lateral ends of the pars

253 dentalis and the pars palatina merge and form a small tongue-and-groove articulation with

254 the anterior end of the maxilla. The alary process is short and thin, perpendicular to the pars

255 dentalis, and only slightly bent posteriorly. Along its posterolateral border it has a reduced

256 articulation with the medial border of the anterior end of the nasal. The alary processess of

257 the premaxillae fall short of the frontal bones and do not contact each other posteriorly;

258 they slightly overlap or lie immediately medial to anteromedial portions of the nasals, and a

259 large fontanelle occurs between them. In European Hydromantes the alary process is

260 considerably longer and is expanded and flattened posteriorly, where it typically slightly

261 overlaps the anteromedial process of the frontal (except in H. italicus, where overlap is

262 found in only $40 \%$ of specimens [Lanza et al., 1995]).

263 Premaxillae of Plethodon and Ensatina generally resemble those of Karsenia; they are

264 fused medially in Aneides, Phaeognathus and Desmognathus. In some Aneides and

265 desmognathines the alary processes become massive and fuse to form a large flat plate that

266 can become heavily coossified with the skin in both Phaeognathus and larger Aneides

267 (Wake, 1966; Means, 1974). The European species of Hydromantes differ from the

268 American species in having much larger alary processes that are often expanded into wing-

269 like structures that reach the frontal bones in all species except $\mathrm{H}$. italicus, in which $60 \%$ of

270 specimens have alary processes that fall short of the frontals (Adams, 1942; Wake, 1966;

271 Lanza et al., 1995). Hydromantes differs from all other genera in that the alary processes

272 never contact each other behind the fontanelle.

273 Maxillae: These paired bones, together with the anteromedial premaxillae, form the upper

274 jaw skeleton (Fig. 3A,E,G). Three regions are recognized. 1) The elongated pars dentalis 
275 extends approximately half the length of the optic fenestra. The entire extent is toothed.

276 The anteriormost part overlaps the posterior area of the pars dentalis of the premaxilla. The

277 posterior part connects to the palatopterygoid cartilage by means of the jugal ligament. 2)

278 The pars facialis, an ascendant process from the pars dentalis, separates the nasal cavity

279 and the optic fenestra. The pars facialis is trapezoidal in shape; its posterodorsal edge

280 overlaps the prefrontal. It has a small extension directed anteriorly and pointing towards the

281 dorsoventral edge of the nasal, but without contacting it. 3) The pars palatina is a flattened

282 plate that extends from the pars dentalis into the oral cavity. It articulates with the pars

283 palatina of the premaxilla and with the vomer, together forming the roof of the palate area.

284 Maxillae in H. platycephalus are less robust than in K. koreana (Fig. 3 B,F,H). The

285 pars dentalis is similar in length, extending to the middle of the optic fenestra, and is fully

286 toothed. The pars facialis is narrowly triangular and concave, the posterior tip of the

287 triangle overlapping the lateralmost edge of the nasals and the partly disconnected anterior

288 part of the frontal (see below for description of the bipartite frontal in Hydromantes). The

289 anteriorly directed process of the pars facialis is absent. The pars palatina is very reduced;

290 it does not contact the vomer at any point. Accordingly, the anterior palate is incomplete

291 and the body of the vomer is weakly connected, if at all, to lateral parts of the palate. In

292 European Hydromantes, the pars facialis is rectangular rather than triangular and much

293 shorter, barely contacting the nasal and well separated by a distinct gap from the frontal

294 (Adams, 1942; Wake, 1966; Lanza et al., 1995).

295 Maxillaries of other plethodontines generally resemble those of Karsenia, especially

296 those of Plethodon and Ensatina, although the pars dentalis of Ensatina is longer and more

297 slender. The pars facialis of Ensatina is small and articulates only weakly, if at all, with the 
298 prefrontal. Maxillae of Aneides are much stouter and are more complexly articulated with

299 the prefrontals and nasals; the pars dentalis is massive in the larger species and in males of

300 smaller ones and bears enlarged teeth anteriorly, while posteriorly it is expanded

301 dorsoventrally and is edentulous (Wake, 1963, 1966; Wake et al., 1983). The maxillae of

302 desmognathines are stout and well articulated via the pars facialis directly to the frontal,

303 which it broadly overlaps. In Phaeognathus there is a very large, stout process that extends

304 posteromedially, almost as far as the quadrate bone, into the ligament that connects the

305 bone to the suspensorium (Wake, 1966).

306 Septomaxillae: These paired bones, embedded in the cartilages of the nasal capsules at the

307 lateral edge of the nasal vacuity, are small and irregular in shape. The anteriormost part is

308 somewhat triangular and projects anteriorly in the dorsolateral part of the nasal cavity (Fig.

309 3A). The small anterior extension of the pars facialis of the maxilla partially covers the

310 septomaxilla. The septomaxilla articulates dorsally with the prefrontal at the anterior edge

311 of the nasolacrimal duct, which passes through its posterior margin.

312 In H. platycephalus, the septomaxillae also are paired structures, irregular in shape and

313 smaller than in Karsenia (Fig. 3B). The bones are weakly ossified and do not articulate

314 with or otherwise contact any other bone.

315 Septomaxillae are typically present in all plethodontines, but usually they are smaller

316 than in Karsenia. They are especially small in desmognathines. The bones are weakly

317 developed in European Hydromantes and can be absent entirely (as many as 60\% of $H$.

318 italicus), absent on one side, or reduced in degree of ossification (Lanza et al., 1995).

319 Nasals: These paired bones are triangular in shape. The base of the triangle forms the

320 dorsal part of the nasal capsule, and the vertex points posterodorsally (Fig. 4A). The nasal 
321 is slightly convex and presents an irregular surface. A foramen is present in the medial part

322 of the bone, presumably for passage of the profundus branch of nerve $\mathrm{V}$. The nasal

323 articulates mesially with the premaxilla and frontal; laterally, it articulates with the

324 prefrontal, which separates it from the maxilla.

325 In H. platycephalus, nasals are more irregular, somewhat rectangular, and less well

326 ossified (Fig. 4B). The nasal has a medial projection that extends anteriorly, contacting the

327 alary process of the premaxilla. Laterally, the nasal articulates with the pars facialis of the

328 maxilla. Anteriorly, the lateral margin of the nasal is notched, forming a partial foramen for

329 the nasolacrimal duct. Nasals are larger and more elongated, usually longer than broad, in

330 European Hydromantes.

$331 \quad$ Nasals are roughly similar in all plethodontines but they are very small and packed

332 between larger bones (e.g., well articulated to the pars facialis of the maxilla and the alary

333 process of the premaxilla) in desmognathines. Shape varies (often specific to a given

334 species) from triangular to quadrangular or pentagonal, and the degree of articulation with

335 the pars facialis of the maxillary varies from close to none among species.

336 Prefrontals: Prefrontals are paired bones, oval and slightly convex, that are irregular in

337 shape. They partially to completely fill the gaps between the orbit and the nasal vacuity,

338 and between the frontal and the pars facialis of the maxilla (Fig. 4A). They are smaller than

339 the nasals. The nasolacrimal duct passes through an elongate foramen in the anterior part of

340 the prefrontal that is usually not enclosed in bone anteriorly. The prefrontal articulates

341 anteriorly with the septomaxilla and lateroventrally with the pars facialis of the maxilla.

342 The prefrontal is overlapped laterodorsally by the nasal; posteriorly, it broadly overlaps the

343 frontals. 
Prefrontals have been reported consistently as absent in Hydromantes (Adams, 1942;

345 Wake, 1966; Lanza et al., 1995). In the specimen scanned, however, the anteriormost part

346 of the frontal seems differentiated as a distinct element (Fig. 4B). This putative element

347 occupies space that represents the anterior part of the frontal and at least part of the

348 prefrontal (in the sense that it is overlapped by the pars facialis of the maxilla). It is not

349 well ossified; the contact between anterior and posterior parts of the frontal is not clearly

350 delimited. An incipient break in the bone extends from the midline, well in advance of the

351 orbits, posterolaterally at about a $45^{\circ}$ angle to the extreme anterolateral border of the orbit.

352 Zones of weak ossification correspond only roughly to the prefrontal because the anterior

353 element extends to the midline, which differs from prefrontals in all other salamanders. The

354 anterior element is posterior to the nasal and is irregular in shape (Fig. 4B). Long but very

355 slender anterior projections are present medially and shorter ones laterally, but the latter

356 does not separate the nasal from the pars facialis of the maxilla, as is typical of prefrontals

357 in many taxa (Wake, 1966). The developmental origin of this putative element should be

358 further explored to clarify the identity and homology of the structure.

359 Prefrontals are absent in desmognathines in which they are thought to be incorporated

360 into expanded facial lobes of the frontal (Wake, 1966). The bones are well developed in

361 Aneides, and in the western species they are involved in a complex interlocking articulation

362 with the pars facialis of the maxilla. The bones of Ensatina and Plethodon resemble those

363 of Karsenia.

364 Frontals: These are long, paired bones, which, together with the parietals, form the roof of

365 the cranial cavity (Fig. 4A). The frontal is rectangular in shape, although its anterior third of

366 is broader than the rest of the bone. It is slightly convex and has a smooth surface. Frontals 
367 articulate mesially with their counterparts but do not fuse. The premaxilla, nasal, and

368 prefrontal overlap the enlarged anteriormost part of the frontal. The lateral edges of the

369 frontal turn down laterally, articulating with the orbitosphenoid (Fig. 6A). Frontals

370 articulate posteriorly with parietals, slightly overlapping them lateroventrally. The

371 articulation is not square, but the contact between frontals and parietals does not leave a

372 conspicuous frontoparietal fontanelle in adults.

373 Frontals in $H$. platycephalus are rectangular structures, enlarged anteriorly (Fig. 4B).

374 They are poorly ossified, especially medially and posteriorly, and the anterior part is

375 weakly connected to the interorbital part of the bone (see above, prefrontal). The frontals do

376 not articulate either with their counterparts or posteriomedially with the parietals, leaving a

377 conspicuous frontoparietal fontanelle that has a shape reminiscent of a fleur-de-lys.

378 Laterally, frontals articulate with the dorsal sides of the orbitosphenoids (Fig. 6C). This

379 articulation extends through the anterior half of the orbitosphenoids. Posterolaterally, the

380 frontals overlap the parietals. In American Hydromantes, a frontal lobe extends

381 anterolaterally, overlapped extensively by the tip of the triangular pars facialis of the

382 maxilla. The lobes are absent in European Hydromantes, but in some individuals the

383 frontals extend as far as the reduced pars facialis of the maxillae.

384 The frontals are well-ossified, large bones in plethodontines. They are particularly

385 large and stout with expanded anterior portions in desmognathines, which lack prefrontals.

386 Desmognathines are unique in that the frontals have ventrolateral processes that invade the

387 antorbital region, in the front of the orbit between the prefrontals and palatal parts of the

388 maxillae. The frontals are relatively massive, especially in Phaeognathus, and they extend

389 beyond the posterior margins of the orbitosphenoids. Usually small, diamond-shaped 
390 fontanelles separate the frontals from each other and the parietals except in desmognathines

391 and larger Aneides. All of the anterior cranial elements of Phaeognathus and Aneides

392 lugubris (and to a lesser extent A. flavipunctatus) are heavily rugose with coossified skin.

393 There is a discrete posterior boundary in the middle of the frontals that corresponds to the

394 anterior extent of the mandibular adductor muscles.

395 Parietals: The parietals are large, rectangular, paired bones that cover the posterior

396 braincase. The parietal is shorter than the frontal and its surface is also more irregular (Fig.

397 4A). The ventrolateral border is curved downward where it contacts the orbitosphenoid and

398 covers the dorsal surface of the ascending process of the palatoquadrate cartilage at the

399 posterior end of the orbitosphenoid (Fig. 6A). This lateral face of the parietal is more

400 conspicuous than that of the frontal. The anterior half of the parietal contacts the

401 orbitosphenoid from the optic fenestra to its posterior end. The broadly curved, posterior

402 border has complex articulations. The ventrolateral border is thickened and becomes

403 clawlike in transverse section, articulating within the claw first with the ascending process

404 and more posteriorly with the inner margins of the otic capsule. The lateral edge becomes

405 thinner posteriorly and conforms to the medial portions of the otic capsule. The anterior

406 surface of the parietal forms a low dome, while the posterior surface, in front of the otic

407 capsule, is depressed and forms a broad groove that accommodates the portion of the

408 mandibular adductor musculature that extends from the atlas vertebra to the mandible. In

409 the scanned specimen there appears to be a significant gap between the two parietals, but in

410 the five cleared-and-stained individuals there is no gap and the bones are sutured. In one

411 instance, there is a clear overlap between the bilateral counterparts. The scanned specimen

412 also displays a small gap between the frontals and the parietals but there is no gap in the 
413 cleared specimens (the scanned and the cleared specimens are all similar in size). The

414 frontals overlap the parietals, especially laterally.

415 In H. platycephalus, parietals are poorly ossified anteromedially and medially (Fig.

$4164 \mathrm{~A})$. The anterolateral edge of each parietal projects anteriorly and is overlapped by the

417 frontal. Laterally, the parietal does not contact the orbitosphenoid except at its posterior end

418 (Fig. 6C). Posteriorly, the parietal envelops the anterior half of the otic capsule. Compared

419 with Karsenia the bone is thinner, flatter and less domed, and the depressed groove

420 accommodating mandibular adductor musculature is less conspicuous.

421 The parietals of Plethodon and Ensatina are similar to Karsenia, while those of

422 Aneides differ mainly in having a more conspicuous posterolateral depression. The paired

423 bones in Aneides are tightly sutured and become fused in large specimens of the larger

424 species. Parietals of desmognathines differ mainly in being more massive and in having

425 even more conspicuous adductor depressions. This reaches an extreme in Phaeognathus, in

426 which the anteromedial portions of the occipito-otic participate in the pronounced

427 depression, with the articulation between parietal and occipito-otic lying at the midpoint of

428 the depression. The parietal and the occipito-otic are drawn out into a large ventrolateral tab

429 that extends the osseous depression for the atlantomandibular ligament, which appears to be

430 unique to desmognathines. The two parietals are strongly sutured in desmognathines. In

431 Desmognathus, but to a lesser extent in Phaeognathus, the two parts of the bone contrast

432 strongly. The bones are relatively short and the anterior half is high, flat and smooth,

433 whereas the posterior half is strongly depressed. The bones are tightly articulated to the

434 frontals and the occipito-otics. 
435 Vomers: The vomers are paired bones that, together with the pars palatina of the maxillae

436 and premaxillae, form the anterodorsal part of the roof of the oral cavity (Fig. 5 A,C,E).

437 Four areas are distinguished. 1) The anterior flattened body articulates squarely with the

438 maxilla and the premaxilla and projects posterodorsally at a $45^{\circ}$ angle. The anterior body

439 does not articulate with its counterpart, leaving an internasal space between them. The

440 mesial edge of the anterior body surrounding the internasal space is turned up, forming a

441 septum-like process that increases in height posteriorly. 2) A short and broad posterior

442 projection proceeds posteriorly from the vomerine body. Its ventrolateral edge surrounds

443 the internal nares. The projection articulates posteromedially with its counterparts. The

444 medial posterior edge of the projection overlaps the anterior edge of the parasphenoid. A

445 topographically limited articulation occurs between the lateral posteroventral part of the

446 vomer and the anteroventral end of the orbitosphenoid (Fig. 5A,E, 6B). 3) A conspicuous

447 dentigerous ridge (dentigerous process, including a preorbital process) extends laterally

448 from the posterior projection toward, but falls short of, the lateral margin of the vomerine

449 body, posterior to the internal nares. 4) A posterior vomerine dental patch is constituted by

450 two patches that meet at the midline, separated from the vomers proper. The patches are

451 drop-shaped and constitute a dense extension of vomerine teeth (see Dentition section for a

452 detailed description). The patches, attached (but not fused) to the ventral surface of the

453 parasphenoid, are separated from the dentigerous process by a narrow gap.

454 The anterior part of the main body of the vomer in H. platycephalus is not as well

455 ossified as that of K. koreana and does not contact the pars palatina of the premaxilla and

456 the maxilla (Fig.5B,D,F). The vomerine body projects posterodorsally at a $45^{\circ}$ angle. The

457 curved, septum-like process on the medial border is absent, and the internasal space is 
458 proportionally larger than in K. koreana. The posterior projection from the main body is 459 slightly curved ventrally. The vomer does not articulate with its counterpart in this male 460 specimen. However, in females there are articulations with the maxilla and premaxilla and 461 also with its counterpart by means of portions of the posterior projections (Adams, 1942).

462 The projection articulates posteriorly with the anteriormost end of the parasphenoid, but 463 there is no contact between the vomer and the orbitosphenoid (Fig 5B, 6D). The 464 dentigerous process projects anteriorly toward the vomerine body; its length exceeds the 465 width of the body. The posterior vomerine dental patches are more reduced than those of $K$. 466 koreana. They are restricted to two narrow, widely separated strips of teeth, located 467 posterolaterally on the ventral surface of the parasphenoid (Fig. 5F). The teeth occupy 468 barely $20 \%$ of the total surface of the parasphenoid, and they are separated from the 469 dentigerous process by a wide gap, three times as great as in Karsenia.

$470 \quad$ Vomers of Plethodon, Ensatina and Aneides closely resemble those of Karsenia in 471 most respects. In large Aneides the septum-like dorsomedial margin of the body may 472 articulate with the ventral surface of the alary process of the premaxilla. The bilateral 473 counterparts articulate with each other for the posterior half of their extent. Preorbital 474 processes of the dentigerous process typically fall short of the lateral extent of the vomer 475 body, but in Ensatina the process is especially long and exceeds the lateral extent of the 476 body. Species of Aneides differ in structure of the preorbital process, which is absent 477 entirely in western species. The gap between the dentigerous process and the posterior tooth 478 patch is typically greater than in Karsenia but less than in Hydromantes, but in Ensatina the 479 gap is less and may be completely closed. The posterior patches are not in contact and are 480 especially widely separated in Ensatina. The vomers of desmognathines have features not 
481 found in other plethodontines and also display much variability related to size of

482 organisms, sex, and habitat. The vomers are generally robust and are tightly articulated to

483 each other. The internasal space is subject to much variation; in the most aquatic, largest

484 species it is much reduced in size and the articulation of the bilateral counterparts is nearly

485 complete. The preorbital process usually has few or no teeth and a bony plate extends

486 posterolaterally from the dental arcade. The preorbital process usually falls far short of the

487 lateral extent of the body. The process may articulate slightly with the peculiar antorbital

488 ossification of desmognathines. The posterior tooth patches are relatively small and are

489 widely separated from the dentigerous portion of the vomer and from each other.

490 Orbitosphenoid: These paired rectangular bones are disposed vertically in an anterior-

491 posterior direction (Fig. 6A,B). They form the lateral sides of the braincase. They are

492 widely separated dorsally and ventrally, and they do not contact each other at any point.

493 Although mainly vertical, they are closer together ventrally than dorsally so that the

494 braincase is trapezoidal in shape anteriorly (Fig. 6B). The inner surface is slightly concave,

495 and the structure is thicker at the anterior and posterior borders. The bone increases in

496 height from the anterior edge to its medial part, decreasing towards its posterior margin.

497 Three foramina for cranial nerves are present (Fig. 6A). The anterior border consists of

498 three projections (one dorsally and two ventrally) that partially encircle the opening of the

499 foramen orbitonasale mediale. A conspicuous optic fenestra lies in the posterior third of

500 the orbitosphenoid. Very large and completely surrounded by bone, it opens at about the

501 level of the articulation of the frontals and parietals. The third foramen, a small foramen

502 oculomotorium, opens posterior to the optic fenestra and close to the posterior margin of

503 the orbitosphenoid. The anteriormost lateral and ventral margins of the orbitosphenoid 
504 contact the posterior edges of the vomers. With the exception of this anterior contact, the

505 ventral surface of the orbitosphenoid contacts the dorsal surface of the parasphenoid (Fig.

506 6B). Dorsally, the orbitosphenoid articulates with the frontal and parietal.

507 The orbitosphenoids in H. platycephalus are more curved and inclined laterally, the

508 cranial cavity being more oval and flattened (Fig. 6C). The foramen orbitonasale mediale is

509 not evident in the anterior part of the orbitosphenoid, and only a slight indication of the

510 anterior part of the foramen oculomotorium is evident at the posterior end of the bone. A

511 conspicuous optic fenestra occupies the posterior area of the orbitosphenoids. The

512 orbitosphenoid articulates ventrally with the anterior half of the parasphenoid; it does not

513 contact the vomer anteriorly (Fig. 6D). The anterior half of the dorsal surface of the

514 orbitosphenoid articulates laterally with the frontal; the posterior half approximates the

515 parietal, although it contacts it only at the posterolateral end.

516 Orbitosphenoids are basically similar in all plethodontines, differing mainly in size and

517 degree of robustness. In Aneides lugubris the bilateral counterparts are in contact

518 posteroventrally.

519 Parasphenoid: The parasphenoid is an unpaired, median, symmetrical bone, which forms

520 the ventral surface of the braincase. Elongated and semi-rectangular, the bone is square and

521 narrow at the anterior margin and wider and more rounded at its posterior end (Fig. 5E). Its

522 anteriormost margin is thin and flat but becomes dorsally concave toward the posterior

523 margin. Several foramina perforate the lateral margin of the parasphenoid in the third

524 quarter of its length. One of these may be the carotid canal, which is not well defined in

525 salamanders; alternatively, all three might carry different branches of the internal carotid.

526 Ventrally, the parasphenoid sustains the vomerine tooth patch, which occupies 
527 approximately $85 \%$ of its surface. The parasphenoid articulates laterally with the

528 orbitosphenoids. The posterior edges curve dorsally, enveloping the anterior borders of the

529 occipito-otic. The posterior end of the bone is expanded dorsoventrally and serves as the

530 attachment for subvertebral muscles.

531 The parasphenoid in H. platycephalus is nearly triangular, with a narrow anterior end

532 (Fig. 5F). It is flat anteriorly, but quickly becomes internally concave, especially at the level

533 of the area occupied by the vomerine tooth patches. The posterodorsal ends articulate with

534 much of the occipito-otic complex.

535 Plethodontines do not differ much with respect to the parasphenoid, but in

536 desmognathines the bone is shortened, thickened and articulates squarely with the ends of

537 the vomer, although a small, flattened process extends forward dorsally. The posterior part

538 of the parasphenoid is greatly expanded and extends far laterally, finally contacting a

539 dorsomedial process of the quadrate.

540 Occipito-otic complex: The posterior portion of the skull is a massive amalgamation of

541 elements associated with the otic capsules and the occipital complex (Fig. 7A,C). The

542 bulbous otic capsules enclose the vestibular-auditory system; they have dorsal and ventral

543 medial connections to each other and the exoccipital region. The otic region is irregular in

544 shape and bears the impressions of the semicircular canals. These impressions form

545 prominent crests, which bear additional projections. The capsule is connected to the

546 braincase by two processes that extend to the base of the ascending process of the

547 suspensorium, by another to the ventral surface of the lateral part of the parietal, and by

548 processes extending to the parasphenoid; it also connects to the basal part of the

549 suspensorium. In addition there is a ridge on the outer surface of the capsule that articulates 
550 with the anterior edge of the squamosal, which also articulates with the capsule behind this

551 ridge. A conspicuous crest, located mesially on the surface of the capsule above the anterior

552 semicircular canal, is v-shaped, the vertex of the ' $\mathrm{v}$ ' pointing anteriorly. Posterolaterally is

553 another prominent crest, directed outward toward the area above the middle of the

554 squamosal. This crest is drawn into a stout process. The posterior part of the capsule is less

555 well ossified. Many foramina pierce the capsule medially toward the cranial cavity,

556 ventrally and posteriorly (the foramina acustica, foramen endolymphaticum, foramen

557 perilymphaticum, and foramen post-oticum). The operculum covering the fenestra ovalis,

558 the pars media plectri, is a circular, well-ossified plate (Fig. 7C). Associated with its lateral

559 side is the columellar stylus of the pars media plectri. The stylus is roughly L-shaped, with

560 an enlarged area in the pars media plectri that connects to the operculum and a relatively

561 large, cylindrical, rod-like portion that proceeds anterolaterally toward the articulation

562 between the squamosal and the quadrate. It does not directly contact these elements,

563 apparently (based on study of cleared specimens) connecting to a long, slender process of

564 the cartilaginous suspensorium and indirectly by a ligament to the squamosal. The

565 exoccipitals form the posteriormost part of the occipito-otic complex, encircling the

566 foramen magnum and articulating via the occipital condyles with the first vertebra. Well

567 ossified and completely fused to the otic capsules, the exoccipitals are in contact dorsally

568 by means of the fibrous tectum synoticum, but they are in direct contact at the posteriormost

569 point. Conspicuous, rounded occipital condyles are concave posteriorly and articulate with

570 the atlantal cotyles. The internal walls of the foramen magnum articulate by means of

571 distinct facets with the large tuberculum interglenoideum of the atlas. The exoccipitals do

572 not contact ventrally, but instead are connected by a rectangular, cartilaginous hypochordal 
573 commissure. The ventral part of each exoccipital is overlapped slightly by the posterior part

574 of the parasphenoid.

575 In H. platycephalus, the otic capsules are enlarged, flattened and well ossified, but

576 disposed similarly to those of $K$. koreana (Fig. 7B,D). The lateral walls of the capsules are

577 swollen and heavily ossified anteromedially at the level of the connections to the

578 orbitosphenoids. The otic capsules have conspicuous dorsal crests that end in small

579 projections that align with the crests of the squamosals.

580 This complex differs little in all plethodontines except for the presence of crests of

581 different sizes and shapes. These reach extremes in the case of high, wing-like crests in

582 large species of Aneides and in males of all species of that genus (Wake, 1963). Crests of

583 the desmognathines have unique configurations and shapes (Wake, 1966). The occipital

584 condyles of desmognathines are massive and prominently stalked (Wake, 1966; Schwenk

585 and Wake, 1993). The opercular-columellar system in plethodontines is relatively uniform.

586 There is a relatively large opercular footplate that appears to be fused (often so completely

587 as to give the impression of a single element) to a more anterior unit comprised of a partial

588 footplate and a distinct rod-like projection. These vary in shape and length among taxa

589 (Monath, 1965; Wake, 1966).

590 Squamosal: The paired squamosals extend from the otic capsules to the quadrates,

591 covering the suspensorium (Fig. 8A). The relatively robust, relatively flattened bone arises

592 just behind the prominent crests on the capsule and descends laterally and slightly

593 anteriorly. Along its path, it undergoes a twist of about $45^{\circ}$ or more. Two-thirds of the

594 internal-proximal surface of the squamosal is also in contact with the enlarged ascending

595 process of the quadrate. 
596

597

598

599

600

601

602

603

604

605

606

607

608

609

610

611

612

613

614

615

616

617

618 ligament.

The squamosal of Hydromantes platycephalus is dog-legged in shape and it is smaller and more slender (Fig. 8B). It is attached to the otic capsule posterior to a prominent crest. It is directed anterolaterally and at about its midpoint it bends sharp laterally and ventrally to articulate with the quadrate.

The squamosals of plethodontines are generally similar, differing mainly in the degree of robustness, which is largely related to the overall strength of jaws and size of the mandibular adductor muscles and associated otic and squamosal crests. The bones reach a maximal size and complexity in large Aneides (Wake, 1963), in which they participate in extended otic crests. The bones are relatively robust in desmognathines, in which the relatively straight bones are tucked behind an otic crest and wedged up against another more horizontally oriented crest of the otic capsule.

Suspensorium: The suspensorium of Karsenia is largely cartilaginous and we have been able to visualize it well with doubly cleared and stained specimens. The only ossified portion is the quadrate and its ascending process, whereas the basal, otic, ascending, and pterygoid portions are cartilaginous. The least well-visualized and smallest portion is the slender, elongate process that connects to the columellar stylus. The quadrate is conspicuous and well ossified, and is a blocky bone (Fig. 8A). It has a relatively long and very thin ascending process that is completely covered by the squamosal. The ventral end of the quadrate is capped in a thick cartilage that forms a concave surface, which articulates with the articular portion of the mandible. The posterior end of the ventral surface forms a small bony projection, the insertion point for the hyoquadrate ligament. Proximally (interior 
619 In H. platycephalus the quadrates are smaller and less robust, although they retain the

620 same generally blocky form (Fig. 8B). The ascending process is shorter.

621 Quadrates of all plethodontids are generally similar, differing mainly in size and degree

622 of development, which is correlated with the overall size of the taxon studied. In

623 desmognathines the quadrates have extended dorsal and medial processes that articulate

624 with the otic capsule and the cartilaginous parasphenoid.

625 Lower jaw: The paired mandibulae form the lower jaw, which is relatively stout and well

626 developed in Karsenia (Fig. 9A). Each ramus contains a well-ossified dentary surrounding

627 a persistent Meckel's cartilage. Viewed laterally each mandible is planar on its ventral

628 surface. The anterodorsal ends of the two dentaries contact at the mandibular symphysis,

629 and they are a bit spread apart ventrally. In transverse section, the dentary is O-shaped

630 anteriorly, enclosing Meckel's cartilage. It opens and increases in height posteriorly,

631 forming an elongated $\mathrm{V}$-shaped region exposing the cartilage at the lingual margin. A well-

632 formed ridge arises along the dorsolateral surface of the dentary at about its midpoint,

633 before the end of the maxilla; this ridge and adjacent parts of the dentary serve as the

634 insertion of more anterior mandibular adductors. The ridge is extended for a short distance

635 posteriorly as a small projection. The dentary rises slightly as the ridge forms but there is

636 no triangular process as in some other plethodontids. Teeth are borne on the dentary from

637 the symphysis region to the origin of the ridge, at the level of the posterior tip of the

638 maxilla, or for about three-quarters of the length of the dentary. The posterior end of the

639 dentary is flattened, narrow, and blade-like, and is closely applied to the prearticular. Each

640 of the paired well-developed prearticulars, located medially to the dentaries, has a long,

641 tapering process that enters the dentary canal so that the bone is inserted into the elongate 
642 triangular opening described above. A moderately high shelf-like coronoid process arises

643 just past the posterior end of the maxilla, immediately adjacent to the dentary ridge, and is

644 inflected dorsomedially. The extensive surface of this shelf is the insertion of more

645 posterior mandibular adductor muscles. The coronoid process extends posteriorly and then

646 rapidly slopes ventrally and flattens, ending just before the posterior end of the prearticular.

647 The posterior portion of Meckel's cartilage, the articular, is enlarged and mineralized or

648 ossified, with a cartilaginous articular surface. The articular is co-ossified with the lateral

649 and posterior parts of the prearticular and is also tightly connected to the dentary.

650 In H. platycephalus the mandible is weaker and more slender (Fig. 9B). In lateral view

651 it is somewhat concave, with the symphyseal region being lower than the articular region.

652 The dentaries are not in direct contact at the mandibular symphysis. The dentary is more

653 slender, but a subdued dorsolateral ridge is present. The ridge is the high point of the

654 dentary viewed laterally, and there is no triangular process. Teeth are present as in

655 Karsenia. The prearticular is smaller and shorter in anteroposterior length, and the coronoid

656 process is sigmoid-shaped in cross-section. The process is relatively low and it slopes

657 rapidly toward the end of the prearticular. The posterior end of the prearticular is drawn

658 into a short rod-like projection. The articular appears to be entirely unossified.

659 Mandibles of plethodontines vary greatly in size but not in composition. Plethodon and

660 Ensatina and the smaller species of Aneides closely resemble Karsenia. Aneides has an

661 edentelous triangular extension of the dentary, anterior to the coronoid process of the

662 prearticular and associated with the muscular dorsolateral ridge. It becomes very large in $A$.

663 lubugris and A. flavipunctatus. The extension is variable but generally low in Plethodon,

664 and only slightly evident in Ensatina. The coronoid process of the prearticular is generally 
665 similar to Karsenia, except in Ensatina, in which it is especially low and small, and

666 Aneides, in which it is enormously enlarged in the larger species. Teeth are borne along

667 about three-quarters of the dentary in Ensatina, between one-half and two-thirds the length

668 in Plethodon, and the sometimes very large teeth of Aneides are restricted to less than one-

669 half to less than one-quarter the length of the dentary (see Dentition section). While the

670 dentaries of the largest Aneides are massive, they are not as massive, in a relative sense, as

671 those of desmognathines. In species such as Phaeognathus hubrichti, the dentaries are very

672 high in lateral view and densely ossified, bearing teeth along less than two-thirds of the

673 length of the bone. A very large dorso-lateral ridge provides a wide shelf for insertion of

674 adductor muscles. The desmognathine prearticular has a unique shape. The coronoid

675 process is restricted to an anterior pointed but stout projection; these form the posterior

676 border of the unique atlantomandibular ligament, which attaches to the dentary just in front

677 of them (Means, 1974). All plethodontids lack a significant retroarticular process, although

678 there is some extension of the prearticular slightly posterior to the articulation. In

679 desmognathines and larger species of Aneides a small ventrally oriented process of the

680 dentary is present near the symphysis, presumable to serve as the point of insertion of hyoid

681 muscles.

682 Hyobranchial apparatus: The hyobranchial apparatus in adults consists of paired

683 ceratohyals, basibranchial, paired radials, paired ceratobranchials I and II, paired

684 epibranchials I, and a urohyal (Fig. 10). All parts of the apparatus are cartilaginous, except

685 the central portion of the basibranchial. The latter is a solid rod of mineralized cartilage

686 viewed laterally in the scanned specimen as floating below the skull, orientated

687 posteroventrally relative to the snout and forming a $45^{\circ}$ angle with the mandibular plane. 
688 The basibranchial is enlarged and has three distinct areas. 1) A central, rod-shaped and

689 mainly mineralized body changes to cartilage both anteriorly and posteriorly. The

690 mineralized portion, which constitutes about $45 \%$ of the total length of the basibranchial,

691 increases in diameter towards the ends. 2) A well-developed, knob-shaped cartilage forms

692 an anterior process. 3) A posterior cartilaginous enlarged area, pointed at the posteriormost

693 end, connects to the two pairs of ceratobranchials. The paired radials articulate at the base

694 of the anterior process of the basibranchial. They are rod-shaped proximally but more

695 flattened and irregular in outline distally. The radials are oriented almost perpendicular to

696 the basibranchial, pointing slightly anteriorly. The first ceratobranchial is the longest

697 articulated structure of the hyobranchial apparatus. Ceratobranchial I is nearly straight, with

698 a relatively flat and broad anterior end, the structure becoming more cylindrical and

699 narrower posteriorly. The anterior end articulates with the basibranchial at the level of the

700 posterior cartilaginous area and the posterior end articulates with epibranchials.

701 Ceratobranchial II is shorter, more slender, slightly sigmoidal, and cylindrical. The anterior

702 end of the ceratobranchial articulates with the basibranchial on two sides of the pointed

703 posterior end. Posterolaterally, the ceratobranchial articulates with the epibranchial.

704 Ceratobranchials I and II do not overlap or contact each other. The epibranchial is a

705 cylindrical cone that decreases in size and curves anteroposteriorly; it is directed

706 posterodorsally, in the direction of the shoulder. The posterior end nearly reaches the level

707 of the pectoral girdle. The bowed, ossified urohyal lies medially, slightly posterior to the

708 level of the epibranchial-ceratobranchial articulation. The ceratohyal is a large element that

709 is cylindrical proximally, where it connects by ligaments to the quadrate. It becomes 
710 flattened and rather abruptly greatly expanded distally, with a broadly rounded anterolateral

711 margin and nearly straight anteromedial margins parallel to the medial axis.

712 The ceratohyal is the longest element of the hyobranchial apparatus (1.7 times the

713 length of the basibranchial), and the first ceratobranchial is the longest of the articulated

714 elements (1.25 time the basibranchial). The second ceratobranchial is 1.2 times the

715 basibranchial, and the epibranchial is about 0.8 times the first ceratobranchial and

716 essentially the same length as the basibranchial. The radials are 0.5 times the basibranchial

717 and the urohyal is 0.3 times the basibranchial. The knob-like anterior extension of the

718 basibranchial (from the midpoint of the attachment of the radials) is about 0.16 times the

719 length of the element. The proportions are similar in all the specimens studied.

720 The hyobranchial apparatus of Hydromantes (all members of the group) differs greatly

721 from that of all other salamanders (Wiedersheim, 1875; Lombard and Wake, 1977; Wake

722 and Deban, 2000), and the contrast with Karsenia is especially great. It has the form of an

723 extremely long projectile. The basibranchial is longer relative to body size than in any other

724 plethodontid and has an anterior extension that is flattened at the end and flexible near the

725 tip (Lombard and Wake, 1977). The basibranchial is expanded near its midpoint with thin

726 lateral flanges. The epibranchials are extremely long, reaching lengths 2.7-3.2 times the

727 basibranchial length. In contrast, the ceratobranchials are short and slender, with the second

728 being slightly shorter and slightly stouter than the first. The first ceratobranchial is only

$7290.52-0.54$ times basibranchial length, whereas the epibranchial is nearly 6 times the length

730 of the first ceratobranchial. Radials and urohyal are absent. The ceratohyals are relatively

731 short, less than 0.9 times basibranchial length, and have only a narrowly expanded blade. 
732 The epibranchials are about three times longer than the ceratohyal. No parts are

733 mineralized.

734 The hyobranchial apparatus of Aneides and Plethodon closely resembles that of

735 Karsenia in shape and proportions, and the basibranchial is mineralized in its midsection in

736 several species. Desmognathus and Phaeognathus also have similar hyobranchial structure,

737 although the tip of the basibranchial is not knobbed in the latter, instead tapering to a point.

738 The radials are somewhat longer and substantially more slender in desmognathines than in

739 the other plethodontines. The urohyal is variable; it can be as long as two-thirds the length

740 of the basibranchial in Desmognathus, but is much shorter and more slender in

741 Phaeognathus. Ensatina differs from other plethodontines in having longer epibranchials

742 (about 1.8 times basibranchial length) and in lacking the slender, knobbed anterior

743 extension of the basibranchial. Instead, that part of the basibranchial is short and

744 trapezoidal-to-triangular in shape. It is partly disconnected from the main body and hence is

745 flexible.

746 Dentition: Toothed areas include the premaxillae, maxillae, dentaries, vomers, and two

747 posterior vomerine patches associated with the parasphenoid. All teeth are pedicellate,

748 small, and barely bicuspid in adults, and nearly homogeneous in size and shape in all the

749 toothed areas. The lingual cusp is the largest. There is scant evidence of sexual

750 dimorphism. Premaxillary teeth are slightly enlarged and reduced in numbers (mean of 7.9

$751+/-1.3$ total for both bones, range of 6-10 in 12 females, $6.4+/-1.1,4-7$ in 8 males) in

752 comparison to such relatives as Plethodon and Ensatina. Maxillary teeth are slightly more

753 numerous in females (mean $49.5+/-4.5,40-56)$ than in males $(45.6+/-3.3,40-50)$.

754 Vomerine teeth are small and extend only a short distance onto the otherwise toothless 
755 preorbital process. They number $16.8+/-2.7,12-20$ in females and $15.5+/-2.6,13-21$ in

756 males. The posterior vomerine patch occupies most of the ventral surface of the

757 parasphenoid, extending forward to the midpoint between the anterior rim of the optic

758 fenestra and the anterior border of the orbitosphenoid; it is densely populated with small

759 bicuspid teeth. Teeth are organized in rows that are oriented anteriorly and form a $45^{\circ}$ angle

760 with the medial sagittal plane of the parasphenoid. The patch narrows to a single tooth in

761 width anteriorly and consists of as many as four roughly parallel rows at the widest site

762 posteriorly. Teeth are difficult to count accurately because there are many unankylosed

763 teeth. Numbers of ankylosed teeth range between approximately 60 and 70 per patch.

764 Replacement teeth are found in the lingual areas of the premaxillae, maxillae, and dentaries, 765 and along the posterolateral margins of the vomerine tooth row.

766 In Hydromantes playcephalus (and other species of the genus) teeth are distributed as

767 in Karsenia. Dentition has been described by Greven and Clemen (1976) and Lanza et al.

768 (1995). Teeth of females and non-reproductive males are similar to those of Karsenia in

769 being obscurely bicuspid and small. The vomers bear teeth nearly to the lateral end of the

770 preorbital process. Posterior vomerine patches are narrower and more widely separated than

771 in Karsenia, but tooth numbers vary from 45-105 (mean 65.4) in H. italicus (Lanza et al.,

772 1995). There are usually between 40 and 50 in American species of Hydromantes.

773 Significant differences in dental morphology are found between European and American

774 species. In the European species males have fewer premaxillary teeth (1-2) than females (3-

775 5), and the teeth are enlarged and monocuspid with sharp, conical, recurved tips that

776 protrude from the mouth and function to scarify the skin of courted females, thus delivering

777 secretions of the mental glands. In the American species females have more premaxillary 
778 teeth that are of normal form, while males have fewer but mainly bicuspid teeth (but not so

779 few as in the European species), although the more posterior teeth are transitional to the

780 shape of the maxillary teeth. Females have maxillary teeth similar to their premaxillary

781 teeth and they number between about 20 and 30 in European species, but they are more

782 numerous in American species (25-40). Males have typical small bicuspid teeth in

783 European species, with about the same numbers as females, but in the American species

784 males have greatly enlarged, monocuspid teeth that protrude outward from the bone and the

785 skin forming the upper lip (Noble and Brady, 1930; Noble, 1931; Adams, 1942). These

786 narrowly conical, sharp maxillary teeth apparently scarify the skin of females during

787 courtship to deliver secretions of mental glands. The maxillary teeth of American males

788 number from 8 to 12 . Dentary teeth of all species are small and bicuspid, numbering

789 between 30 and 50 .

790 Dentition in Desmognathus and Phaeognathus was described by Means (1974) and

791 in general resembles that of Karsenia. However, there is substantial interspecific variation

792 in the shape and size of tooth crowns. Typical bicuspid teeth are present, but lingual cusps

793 of some species are enlarged and recurved, and in a few species the labial cusp is greatly

794 reduced in size and is nearly imperceptible. Some species display sexual dimorphism in

795 cusp morphology, with females having typical small bicuspid teeth and males developing

796 monocuspid conical premaxillary teeth that project forward, and enlarged, forward

797 projecting teeth at the anterior end of the dentary that have hypertrophied lingual cusps

798 (Noble and Pope, 1929). In two species, teeth of the jaws have short flattened cusps that

799 have been described as fungiform (Means, 1974). The dentaries of some species become

800 concave and may even lose most teeth at sexual maturity. Ensatina resembles Karsenia in 
801 dentition but has higher numbers of generally smaller but clearly bicuspid teeth. No sexual

802 dimorphism has been noted. The vomerine tooth series is especially long, and the posterior

803 vomerine tooth patches are large, narrowly separated, and bear high numbers of teeth.

804 Plethodon resembles Karsenia in most respects but has more diversity of crown shapes. In

805 general larger species have more teeth, with numbers of maxillary teeth varying between 30

806 and 80 for different species (Coss, 1974). Most teeth are simple and bicuspid, but in males

807 of some species (eastern small group) premaxillary and anterior maxillary teeth are

808 elongated and have enlarged labial cusps. In most of the western species premaxillary teeth

809 are monocuspid and spike-like, and in some species these teeth are also found on the

810 maxilla, especially anteriorly; in P. elongatus and P. stormi these anterior maxillary teeth

811 are less elongated but enlarged and flattened, even in females (Coss, 1974). The dentition

812 of Aneides is similar to that of Karsenia in respect to vomerine teeth, which are small and

813 bicuspid. However, western species of Aneides have especially small vomerine teeth and

814 the row is short because the preorbital process of the vomer is absent (Wake, 1963). Teeth

815 of the jaws differ substantially from those of Karsenia. The species that most closely

816 resembles Karsenia is $A$. hardii, the females of which have relatively small, bicuspid

817 premaxillary, maxillary and dentary teeth (Wake, 1963). Male A. hardii have premaxillary

818 teeth that are monocuspid, elongated and recurved; anterior maxillary and dentary teeth are

819 small and bicuspid, but posteriorly on the maxilla the teeth become longer and are laterally

820 compressed with an obscure or absent labial cusp (Coss, 1974). Adult A. aeneus has

821 monocuspid and "spike-like" teeth (Coss, 1974) and bicuspid teeth are observed only in

822 juveniles. The western species, A. ferreus, A. flavipunctatus, A. lugubris and A. vagrans, all

823 have specialized dentition, with small bicuspid premaxillary teeth in females but 
824 monocuspid premaxillary teeth in males ("needle-like" in A. flavipunctatus; Coss, 1974),

825 and enlarged, recurved and laterally compressed maxillary and dentary teeth, although

826 anterior maxillary teeth may be small and bicuspid. The posterior part of the maxilla is

827 toothless and greatly expanded dorsoventrally, and the monocuspid teeth immediately in

828 front of this expanded portion are large and blade-like (Wake, 1963). In A. lugubris,

829 maxillary and dentary teeth both increase in size and degree of compression and decrease in

830 number with increasing body size, with as few as five per bone in large adults (Wake et al.,

831 1983). Numbers of maxillary and dentary teeth are reduced to as few as three per bone in $A$.

832 flavipunctatus (Wake, 1963).

833

\section{DISCUSSION}

835 Modern salamanders constitute an old clade that originated by the Triassic;

836 diversification of the extant families traces from the Jurassic to the mid-Cretaceous (Vieites

837 et al., 2009). Salamanders have invaded heterogeneous geographic regions, inhabiting a

838 vast array of terrestrial and aquatic habitats. Furthermore, they have experienced very

839 different cycles of climatic and environmental conditions since their origin. However, the

840 characteristic general morphology of salamanders has persisted for more than 160 million

841 years (Gao and Shubin, 2003). This morphological persistence despite profound

842 environmental changes has been related to the characteristic biology of these organisms

843 (Wake et al., 1983; Larson, 1984; Wake and Larson, 1987).

844 Variations, needless to say, occur. Morphological diversity among salamanders

845 reflects adaptations to specific habitats, as well as the evolution of highly specialized life

846 histories, such as direct development and paedomorphosis. These variations characterize 
847 the distinct families of salamanders, and, occasionally, within-family clades (Wake, 1966;

848 Larson, 1984). Nonetheless, the morphological 'solutions' that have evolved are, in several

849 cases, rather similar among clades, leading to a pattern of rampant homoplasy within the

850 group (Wake, 1991).

851 Homoplasy, the independent evolution of similar features without a common ancestry,

852 is ubiquitous in Caudata. Moreover, it is not restricted to any taxonomic-phylogenetic level,

853 but it can be detected at diverse phylogenetic depths. The extensive homoplasy has made

854 phylogenetic reconstruction problematic (e.g., Wake, 1966; Mueller et al., 2004; Wiens et

855 al., 2005). The monophyly of the ten families of salamanders has been confirmed with

856 morphological, molecular and paleontological data. The phylogenetic relationships among

857 families, however, have been more difficult to establish, especially when using only

858 morphological characters, because of the high levels of homoplasy. For example,

859 paedomorphic forms, in which individuals are sexually mature but retain a larval

860 morphology, have independently evolved in several families of salamanders. The retention

861 of larval characters in 'adult' individuals and the absence of diagnostic adult characters in

862 these individuals have obscured the attempts to reconstruct the phylogenetic relationships

863 between families by means of standard morphological characters (Good and Wake, 1992;

864 Larson and Dimmick, 1993; Gao and Shubin, 2001; Wiens et al., 2005). Furthermore, the

865 evolution of homoplastic features is also substantial within families, in particular the

866 Plethodontidae (Larson, 1984; Wake, 1991; Parra-Olea and Wake 2001).

867 The Family Plethodontidae comprises more than two thirds of all the species of

868 salamanders, and is the most speciose clade among salamanders. The family originated

869 around 125 mya (divergence between Amphiumidae and Plethodontidae; Vieites et al., 
870 2009). The evolutionary history of plethodontids has been characterized by several

871 successful radiations. In some cases, the radiations entailed the geographic expansion and

872 diversification of the group, but with no substantial change in the morphology and ecology

873 of the lineage (non-adaptive radiation). The genus Plethodon includes more than 50 species

874 distributed in western and eastern North America, all occupying similar habitats and niches

875 (Kozak et al., 2006). Morphology is generally conserved among species of Plethodon, with 876 no significant differences except in coloration, relative sizes and proportions (Wake et al.,

877 1983; Kozak et al., 2006). This scenario contrasts with the adaptive radiation that permitted

878 the expansion southward and the colonization of the New World tropics by the supergenus

879 Bolitoglossa, which includes more than 250 species of plethodontid salamanders (Wake,

880 1987). The bolitoglossine radiation entailed the invasion of new niches and habitats and the

881 evolution of new behavioral and morphological specializations. Highly specialized and

882 derived forms also occur in smaller clades such as the genus Aneides, which includes

883 species with the strongest and most specialized jaws of the family, and Phaeognathus,

884 which has a highly derived and heavily ossified skull related to its burrowing behavior.

885 Diversity and disparity are thus not correlated within the family, and generalists and

886 specialists are unevenly distributed across the phylogeny (Larson, 1984). The diversity of

887 forms and specializations has evolved along only a few morphological axes, constrained by

888 a persistent morphological design and leading to the homoplastic pattern observed within

889 the family (Wake, 1991).

890 The discovery of Karsenia koreana, the only Asiatic plethodontid, not only has

891 challenged our understanding of the biogeographic history of plethodontid salamanders, but

892 also is of relevance in comprehending the evolution of morphological patterns and trends 
893 within the family. We discuss the anatomical description of $K$. koreana with two goals in

894 mind. First, we approach the biology of the species through its morphological description,

895 profiting from the detailed comparative data set available for most plethodontid species.

896 The general, global links among anatomical parts, functional morphology, and ecological

897 characteristics of the different species are well understood (Wake, 1966; Larson, 1984).

898 Then, we analyze the morphological trends observed in $K$. koreana and its closest relatives

899 to examine the potential factors that have driven the evolution of morphology in

900 plethodontids.

901

902 Habitat in Relation to the General Morphology of the Skull

903 There is a broad correlation between the general morphology of the skull and the habitat of

904 plethodontine salamanders. For example, species within Plethodon are generally ground-

905 dwellers, and are normally found under rocks and logs in forest habitats. The morphology

906 of their skulls represents the most generalized and likely ancestral form (Wake, 1966). The

907 Plethodon radiation contrasts with other functionally specialized types such as occur in

908 Desmognathus, which has flattened and streamlined skull morphologies adapted for living

909 in mountain streams, and the robust and bullet-shaped skull in the burrower Phaeognathus

910 (Wake, 1966; Larson, 1984; Schwenk and Wake, 1993).

911 The skull of Karsenia is compact and well articulated. Jaws are robust although teeth are

912 not enlarged. In general the skull resembles that of members of the genus Plethodon more

913 than that of other plethodontine genera. It is apparently stronger than any Plethodon skull

914 that we have observed, resembling that of members of the P. elongatus group more than

915 others in this respect. It lacks, however, the crests on the occipito-otic that receive a peg- 
916 like projection of the squamosal, which is unique to members of that latter group (Wake,

917 1963). Like Plethodon, Karsenia is thought to be fully terrestrial, living at or near the

918 surface, but unlike most Plethodon it is associated with rock crevices as its vernacular

919 name, Korean crevice salamander, implies. The species of Plethodon that share this habit to

920 some degree include P. larselli (P. vandykei group) and P. asupak ( . elongatus group;

921 Mead et al., 2005). Although behavior of Karsenia koreana in relation to habitat use is

922 known only from the observations of collectors, we suspect that the species uses its solid

923 skull in part in relation to seeking refuge in tight spaces between rocks.

924 The skull of Hydromantes is similar to that of Karsenia in general composition, but in

925 overall shape and degree of ossification it is the plethodontine genus that is most distinct. In

926 contrast to the rounded, strong skull of Karsenia, that of Hydromantes platycephalus, as

927 revealed in the CT scans and confirmed in the cleared and stained specimens, is

928 dorsoventrally compressed and weakly articulated. The contrast is greatest in sexually

929 mature males: the skull is especially flattened with maxillae that are oriented ventrolaterally

930 and bear elongated, spine-like teeth that extend laterally well beyond the margins of the

931 head (first noted in the original description; Camp, 1916). Hydromantes and especially $H$.

932 platycephalus wedge themselves into very tight spaces, but generally in cracks in massive

933 outcrops of granite. Rather than having evolved a heavily ossified skull, they appear to have

934 followed an alternative adaptive route in which the skull gives way to pressure and

935 conforms, to a degree, to its incompressible surroundings.

936

937 Feeding in Relation to Skull Form and the Anatomy of the Hyobranchial Apparatus

938 Feeding systems include the jaws, the dentition, the tongue, and the tongue skeleton, i.e., 
939 the hyobranchial apparatus. Feeding systems and behaviors are highly diverse in

940 Plethodontidae, related to the different habitats and life styles of the species. The

941 diversification of feeding mechanisms, in fact, has played a substantial role in the evolution

942 of the family (Lombard and Wake, 1976, 1977, 1986; Roth and Wake, 1985).

943 The hyobranchial apparatus in salamanders is involved in respiration and feeding during

944 the larval period, and in pulmonary respiration in terrestrial adults. The evolutionary loss of

945 lungs in plethodontid salamanders, coupled with the evolution of direct development in

946 most of the species, permitted the use of the hyobranchial apparatus in highly specialized

947 methods of feeding, such as tongue projection. The hyobranchial apparatus, released from

948 its functional constraints, has repeatedly evolved highly derived feeding mechanisms within

949 the family (Wake, 1991). Feeding mechanisms are grouped in three main categories:

950 attached protrusible tongues (ancestral condition; e.g., Plethodon, Aneides), attached

951 projectile tongues (e.g., Ensatina, Batrachoseps, Hemidactylium), and free projectile

952 tongues (most derived condition, e.g., Hydromantes, Eurycea, Bolitoglossa) (Lombard and

953 Wake, 1986). The structure, extent of ossification, and proportions among elements of the

954 hyobranchial apparatus are highly modified in each of the three categories. These changes

955 are accompanied by concomitant changes in the associated jaw musculature and

956 articulation (Lombard and Wake, 1976; Hinderstein, 1971; Schwenk and Wake, 1993).

957 Karsenia koreana represents the ancestral condition, with a protrusible attached tongue

958 and a hyobranchial apparatus similar in shape and proportions to that of Plethodon and

959 Aneides. We know nothing concerning the feeding behavior of Karsenia, but based on the

960 close resemblance of the tongue and hyobranchial apparatus to that of Plethodon and on the

961 absence of the highly modified jaws of desmognathines, we assume that it feeds by 
962 contacting the prey with its protrusible tongue and then rapidly delivering the prey to the

963 buccal cavity, where it is held by means of the posterior vomerine tooth patches and the

964 tongue (Maglia and Pyles, 1995; Wake and Deban, 2000). All plethodontines feed mainly

965 on arthropods, usually of small size in relation to the size of the mouth. Teeth and jaws play

966 a minor to negligible role in prey capture and processing in other plethodontines, except

967 when prey are large. While Hydromantes also uses tongue-feeding, it is specialized to an

968 extreme degree and has the longest and at the same time the most powerful tongue of any

969 salamander yet studied (Deban et al., 1997; Deban et al., 2007). Its relatively weak jaws do

970 not appear to play a role in processing of food.

971 Hydromantes has been well studied with respect to visual behavior and feeding (Roth,

972 1976, 1987). The eyes are large and protuberant and the head is mobile. Associated with

973 head mobility is a small and gracile tuberculum interglenoideum on the atlas vertebra,

974 which extends into the foramen magnum and has small articular facets, oriented

975 ventrolaterally. We know little concerning head mobility in Karsenia, but its large and

976 robust tuberculum interglenoideum suggests that it is associated with less craniovertebral

977 mobility and increased resistance to bending than in Hydromantes and possibly other

978 plethodontines as well. The extreme in reduction of the tuberculum interglenoideum is in

979 desmognathines, in which the occipital condyles are enlarged and stalked, thus moving the

980 head away from the vertebral column and facilitating up-and-down movements of the head

981 (Schwenk and Wake, 1993).

982 Whereas the skull of Karsenia is rather solidly built and cylindrical, with a high, well-

983 supported braincase and relatively small orbits, that of Hydromantes is relatively light and

984 flat with weak articulations of bones, and its jaws are light and lack strong musculature and 
985 bear teeth that are directed outside the mouth. The braincase of Hydromantes is weakly

986 supported, the jaws are weak and the orbits are especially large. Together with the

987 flattening of the entire skull, the impression is of a skull that is not involved in food

988 processing, as is appropriate for an organism with an elongate, highly specialized tongue

989 that delivers the prey toward the back of the buccal cavity where it is immobilized by the

990 posteriorly directed vomerine tooth patches.

991

992 Secondary Sexual Traits of the Skull in Relation to Courtship and Mating Behavior

993 Courtship behavior is uniform among plethodontids (summaries in Arnold, 1977; Wells,

994 2007). During an elaborate tail-stradding walk, the male delivers one or a few

995 spermatophores that are taken into the female's cloaca. The tail-stradding behavior is

996 usually accompanied by the delivery of pheromones by the male. Two distinct modes of

997 delivery have been described. In the first mode, which is assumed to be ancestral and more

998 generalized among plethodontid salamanders, males deliver pheromones from their mental

999 glands by means of scratching the dorsal skin of females with their seasonally

1000 hypertrophied premaxillary teeth. Species showing this 'vaccination' behavior have a strong

1001 seasonal sexual dimorphism in dentition. A second derived mode of pheromone transfer has

1002 evolved in a clade of the large species of Plethodon. In this case, males do not develop the

1003 protruding premaxillary teeth and the delivery of pheromones is conducted by repeatedly

1004 touching the mental gland to a female's nares. Courtship and mating behavior in most of the

1005 plethodontid species studied to date involve the delivery of pheromones, although a few

1006 species have secondarily lost the mental glands and the delivery behavior (e.g., Ensatina)

1007 (Arnold, 1977; Wells, 2007). 
1008 There is scant evidence of sexual dimorphism in our material of Karsenia, whereas most

1009 species of plethodontines show at least seasonal sexual dimorphism in premaxillary teeth,

1010 males having fewer and larger teeth (Coss, 1974). In our seasonally limited samples of

1011 Karsenia, although the premaxillary teeth of males are only slightly enlarged and, while

1012 fewer in number in males than in females, the minimum number of 4 per bone is not

1013 especially low. However, larger series of males and females must be studied to assess the

1014 degree of seasonality and sexual dimorphism in the premaxillary dentition of Karsenia.

1015 Nothing is known concerning courtship and mating in Karsenia but, given the absence of

1016 protruding premaxillary teeth and the presence of mental glands in males, it is reasonable to

1017 assume that they are similar to the derived mode observed in Plethodon. The situation is

1018 similar in the European species of Hydromantes, but in the American species sexual

1019 dimorphism is expressed in a unique way. The maxillary teeth of males are at least

1020 seasonally enlarged and spine-like. While their precise role in courtship has not been

1021 specifically studied, based on behavior in other plethodontids it is likely that the teeth are

1022 used to vaccinate females with pheromonal secretions from the mental glands.

1023

1024 Morphology of the Skull with Respect to Social and Aggressive Behavior

1025 Patterns of social and aggressive behaviors are extremely diverse among plethodontids,

1026 involving visual and chemical cues in species, sexual, and individual recognition. Agonistic

1027 behaviors are normally related to intraspecific territorial combat, but also to interspecific

1028 spacing strategies and parental care (Jaeger and Forester, 1993). Plethodontines are known

1029 to be aggressive, both toward sympatric congeners and to conspecifics (reviewed in Wells,

1030 2007). In some cases, the morphological correlates of aggressive behavior have been 
1031 studied in detail (e.g., Staub, 1993; Wiltenmuth, 1996). The relatively strong jaws of

1032 Karsenia, which might be related either to locomotor use of the head or to feeding, suggest

1033 that these forms may be aggressive. However, scarring has not been observed in the

1034 specimens collected to date, so no further conclusions can be extrapolated. Aggression has

1035 not been observed in Hydromantes and it is not expected, given the weakness of the jaws.

1036 One must be cautious in inferring function from form in these salamanders, however,

1037 because the relatively weak-jawed Ensatina can be very aggressive toward conspecifics

1038 (Wiltenmuth, 1996; Wiltenmuth and Nishikawa, 1998).

1039

1040 Phylogenetic Implications of Comparative Skull Morphology in Plethodontine

1041 Salamanders

1042 The skulls of the genera of plethodontine salamanders are distinctive, within a framework

1043 of conservative composition (see below). Furthermore, even within genera such as Aneides

1044 (Wake, 1963), Desmognathus (Means, 1974), and Hydromantes (Wake, 1966; Lanza et al.,

1045 1995; this work) important differences characterize either individual species or small clades

1046 (such as the western species of Aneides, and the European as compared with the American

1047 Hydromantes). Some multispecies genera, e.g. Aneides, Hydromantes, and Desmognathus,

1048 are characterized by numerous synapomorphies (Wake, 1966), but Plethodon is not (Wake,

1049 1963). Plethodon is the second largest genus of salamanders (after Bolitoglossa), currently

1050 with 55 recognized species (AmphibiaWeb, September, 2009.

1051 http://amphibiaweb.org/index.html). These species are remarkably uniform, with relatively

1052 minor differences among them; only the P. elongatus group has significant synapomorphies

1053 associated with the jaws, squamosal, and cranial crests (Wake, 1963, and unpublished 
1054 data). Furthermore, Plethodon displays apparently plesiomorphic states for most skull and

1055 hyobranchial characters, the only exceptions being the somewhat strengthened jaws and

1056 slightly reduced numbers of teeth, which distinguish it from Ensatina and from distant

1057 outgroups such as Rhyacotriton. Karsenia also is plesiomorphic with respect to nearly all

1058 traits of the skull and hyobranchial apparatus, the exceptions being the strong jaws and the

1059 ossified first basibranchial. It shares the latter and its plesiomorphic traits with at least some

1060 species of Plethodon; with respect to skull and hyobranchial morphology Karsenia would

1061 fit well within Plethodon. The major features separating the genera relate to tarsal anatomy

1062 (Min et al., 2005) and molecular characters (Min et al., 2005; Vieites et al. 2007).

1063 We attempted a phylogenetic analysis of data from the skull and hyobranchial

1064 apparatus, with characters used by Wake $(1963,1966)$, Good and Wake (1992), Larson and

1065 Dimmick (1993), and Wiens et al. (2005), but to little effect (data not shown). Larson and

1066 Dimmick and Wiens et al. attempted to reconstruct the phylogenetic relationships among

1067 salamander families, but even at that phylogenetic level many of the morphological

1068 characters employed were not informative due to the great amount of homoplasy among

1069 and within lineages. The majority of the characters used for the phylogentic analysis, as

1070 expected, were not informative at the phylogenetic depth of this study. There are very few

1071 synapomorphies in the dataset, the most numerous being those that support the

1072 Desmognathus, Aneides, and Hydromantes clades. The sole multigeneric clade supported

1073 with several synapomorphies is Phaeognathus + Desmognathus. This clade, long

1074 recognized taxonomically as the subfamily Desmognathinae (Wake, 1966), was recently

1075 and unexpectedly found to be deeply nested within the Plethodontinae in all relevant 
1076 molecular analyses (e.g., Mueller et al., 2004; Chippindale et al., 2004; Vieites et al., 2007).

1077 No single morphological synapomorphy defines a Karsenia-Hydromantes clade.

1078 Composition of the skull of plethodontine salamanders is remarkably conservative.

1079 The divergence of the two major clades of plethodontid salamanders, Plethodontinae and

1080 Hemidactyliinae, is approximately 94 mya (Vieites et al., 2007; Zhang and Wake, 2009).

1081 During that vast period of time, in which the range of the plethodontines expanded from

1082 North America to east Asia and Mediterranean Europe, very little compositional change in

1083 skull configuration has taken place. Septomaxillary bones are variably absent from some

1084 populations of European Hydromantes, prefrontals are absent from desmognathines and

1085 Hydromantes, and urohyals and radii of basibranchials are absent from Hydromantes.

1086 Premaxillary bones are fused in Aneides, Desmognathus and Phaeognathus. Otherwise all

1087 species share a common composition. There are differences in degree of ossification,

1088 general strength of the skull and in desmognathines a major change in the jaw-opening and

1089 feeding and locomotory mechanisms associated with the skull. The putative sister-taxon

1090 relationship of Karsenia and Hydromantes associates the apparently conserved, likely

1091 ancestral condition of the skull and hyobranchial apparatus in Karsenia with the extreme of

1092 specialization for tongue feeding and the weakest and most compositionally deficient

1093 plethodontine skull of Hydromantes.

1094 The pattern of generalist-specialized forms within clades is repeated along the phylogeny

1095 of plethodontids, and the clade comprising Karsenia and Hydromantes provides a new

1096 example with which to analyze the processes driving morphological evolution and

1097 specialization in Plethodontidae. As discussed, homoplasy, frequent within and between

1098 salamander families, makes attempts at phylogenetic reconstruction problematic at all 
1099 phylogenetic levels. Homoplastic patterns, which are non-randomly distributed both among

1100 characters and among taxa, reflect real biological processes that underlie the recurrent

1101 evolution of morphological similarities among groups (Hufford, 1996; McShea, 1996). In

1102 salamanders, these processes include the modification of otherwise conserved

1103 developmental programs (e.g., ontogenetic repatterning, differential metamorphosis [Roth

1104 and Wake, 1985; Wake and Roth, 1989]). In Plethodontidae, these developmental

1105 modifications, coupled with extreme life history strategies such as paedomorphosis and

1106 especially direct development, and morphological peculiarities such as the loss of lungs,

1107 created an unusual evolutionary arena that permitted the diversification of the group but

1108 within a framework of homoplasy and morphological constraint (Wake et al., 1983; Wake,

1109 1991; Wake and Hanken, 1996). Descriptions of new lineages, such as K. koreana, are

1110 important because they test our understanding of the limits of morphological diversity, and

1111 provide insight into the dimensions of evolutionary patterns within bounds, or constraints,

1112 on change. Our anatomical description of the skull of the only Asiatic plethodontid is

1113 conducted within this conceptual framework. Obtaining relevant biological information for

1114 the species, such as habitat use, feeding habits, and life history traits, will enable us to

1115 extend analysis of plethodontid evolution in a multidimensional approach (Wake and

1116 Larson, 1987), enhancing our understanding of the relative importance of the processes that

1117 have driven the evolution and diversification of plethodontid salamanders. A more general

1118 outcome of our study will be progress toward an understanding of how lineage

1119 differentiation proceeds in the context of limits to morphological expression and apparent

1120 phylogenetic and developmental constraints.

1121 


\section{ACKNOWLEDGEMENTS}

1123 We are deeply grateful to Jessica Maisano and the members of the DigiMorph CT scan

1124 facilities at the University of Texas, Austin, for their help with the scanning and

1125 segmentation processes. D. Vieites and R. Bonett collected the Karsenia; Sean Rovito

1126 collected the Hydromantes platycephalus that was scanned. We also acknowledge the

1127 assistance of M. S. Min and the late S. Y. Yang, and the agencies that provided the

1128 necessary collecting permits. James Hanken and an anonymous reviewer contributed

1129 numerous comments that greatly improved the manuscript. This research was supported by

1130 the Amphibian Tree of Life grant (National Science Foundation EF-0334939).

1132 REFERENCES

1133 Adams L. 1942. The natural history and classification of the Mount Lyell salamander, 1134 Hydromantes platycephalus. Univ Calif Pub Zool 46:179-204.

1135 Arnold SJ. 1977. The evolution of courtship behavior in New World salamanders with 1136 some comments on Old World salamanders. In: Taylor DH, Guttman SI, editors. The 1137 Reproductive Biology of Amphibians. New York: Plenum Press. p 141-183.

1138 Camp CL. 1916. Spelerpes platycephalus, a new alpine salamander from the Yosemite 1139 National Park, California. Univ Calif Pub Zool 17:11-14.

1140 Chippindale PT, Bonett RM, Baldwin AS, Wiens JJ. 2004. Phylogenetic evidence for a 1141 major reversal of life-history evolution in plethodontid salamanders. Evolution $1142 \quad 58: 2809-2822$. 
1143 Coss HT. 1974. Maxillary and premaxillary dentition of salamanders of the tribe

1144 Plethodontini (Family Plethodontidae) [Ph.D. Dissertation]. Clemson (SC): Clemson

$1145 \quad$ University. ix $+70 \mathrm{p}$.

1146 Crochet PA. 2007. Nomenclature of European plethodontid salamanders: Speleomantes

1147 Dubois, 1984 has precedence over Atylodes Gistel, 1868. Amphibia-Reptilia 28:170-

$1148 \quad 172$.

1149 Deban SM, O'Reilly JC, Dicke U, van Leeuwen JL. 2007. Extremely high-power tongue

1150 projection in plethodontid salamanders. J Exp Biol 210:655-667.

1151 Deban SM, Wake DB, Roth G. 1997. Salamander with a ballistic tongue. Nature 389:27-

$1152 \quad 28$.

1153 Francis ETB. 1934. The Anatomy of the Salamander. Oxford: Clarendon Press. p 381, 25

$1154 \quad$ pls.

1155 Frost DR, Grant T, Faivovich J, Bain RH, Haas A, Haddad CF, de Sá RO, Channing A,

1156 Wilkinson M, Donnellan S, Raxworthy CJ, Campbell JA, Blotto BL, Moler P,

1157 Drewes RC, Nussbaum RA, Lynch JD, Green DM, Wheeler WC. 2006. The

1158 Amphibian Tree of Life. Bull Am Mus Nat Hist 297:1-371.

1159 Gao KQ, Shubin NH. 2001. Late Jurassic salamanders from China. Nature 410:574-577.

1160 Gao KQ, Shubin NH. 2003. Earliest known crown-group salamanders. Nature 422:424$1161 \quad 428$.

1162 Good DA, Wake DB. 1992. Geographic variation and speciation in the Torrent

1163 Salamanders of the genus Rhyacotriton (Caudata: Rhyacotritonidae). Univ Calif Pub

1164 Zool 126:1--91. 
1165 Greven H, Clemen G. 1976. Morphologische Untersuchungen an der Mundhöhle von

1166 Urodelen. II. Die Gaumenzahnfelder von Hydromantes italicus Cunn

1167 (Plethodontidae: Amphibia). Zool Beitr 22:489-506.

1168 Hilton WA. 1945. The skeleton of Hydromantes. J Ent Zool 37:98-99.

1169 Hinderstein B. 1971. The desmognathine jaw mechanism (Amphibia: Caudata:

1170 Plethodontidae). Herpetologica 27:467-476.

1171 Hufford L. 1996. Ontogenetic evolution, clade diversification, and homoplasy. In:

1172 Sanderson MJ, Hufford L, editors. Homoplasy: The Recurrence of Similarity in

1173 Evolution. San Diego: Academic Press. p 271-301.

1174 Jaeger RG, Forester DC. 1993. Social behavior of plethodontid salamanders. Herpetologica $1175 \quad 49: 163-175$.

1176 Kozak KH, Weisrock DW, Larson A. 2006. Rapid lineage accumulation in a non-adaptive 1177 radiation: phylogenetic analysis of diversification rates in eastern North American

1178 woodland salamanders (Plethodontidae: Plethodon). Proc R Soc Lond B 275:539$1179 \quad 546$.

1180 Lanza B, Caputo V, Nascetti G, Bullini L. 1995. Morphological and genetic studies of the 1181 European plethodontid salamanders: taxonomic inferences (genus Hydromantes). 1182 Monogr Mus Reg Sci Nat 16:1-366.

1183 Larson A. 1984. Neontological inferences of evolutionary patterns and processes in the 1184 salamander family Plethodontidae. Evol Biol 17:119-217.

1185 Larson A, Dimmick WW. 1993. Phylogenetic relationships of the salamander families: an 1186 analysis of congruence among morphological and molecular characters. Herp Monogr $1187 \quad 7: 77-93$. 
1188 Leopold JL, Maglia AM, Pugener LA, Gauch S. 2007. The Amphibian Anatomical

1189 Ontology web project. http://www.amphibanat.org

1190 Lombard RE, Wake DB. 1976. Tongue evolution in the lungless salamanders, family

1191 Plethodontidae. I. Introduction, theory and a general model of dynamics. J Morphol $1192 \quad 148: 265-286$.

1193 Lombard RE, Wake DB. 1977. Tongue evolution in the lungless salamanders, family

1194 Plethodontidae. II. Function and evolutionary diversity. J Morphol 153:39-80.

1195 Lombard RE, Wake DB. 1986. Tongue evolution in the lungless salamanders, family

1196 Plethodontidae. IV. Phylogeny of plethodontid salamanders and the evolution of 1197 feeding dynamics. Syst Zool 35:532-551.

1198 Maglia AM, Leopold JL, Pugener LA, Gauch S. 2007. An anatomical ontology for 1199 amphibians. Proc Pac Symp Biocomp 12:367-378

1200 Maglia AM, Pyles RA. 1995. Modulation of prey-capture behavior in Plethodon cinereus 1201 (Green) (Amphibia: Caudata). J Exp Zool 272:167-183.

1202 McShea DW. 1996. Complexity and homoplasy. In: Sanderson MJ, Hufford L, editors. 1203 Homoplasy: The Recurrence of Similarity in Evolution. San Diego: Academic Press. $1204 \quad$ p 207-225.

1205 Mead LS, Clayton DR, Nauman RS, Olson DH, Pfrender ME. 2005. Newly discovered 1206 populations of salamanders from Siskiyou County California represent a species 1207 distinct from Plethodon stormi. Herpetologica 61:158-177.

1208 Means DB. 1974. The status of Desmognathus brimleyorum Stejneger and an analysis of 1209 the genus Desmognathus (Amphibia: Urodela) in Florida. Bull Florida State Mus $1210 \quad 18: 1-100$. 
1211 Min MS, Yang SY, Bonett RM, Vieites DR, Brandon RA, Wake DB. 2005. Discovery of 1212 the first Asian plethodontid salamander. Nature 435:87-90.

1213 Monath T. 1965. The opercular apparatus of salamanders. J Morphol 116:149-170.

1214 Mueller R, Macey JR, Jaekel M, Wake DB, Boore JL. 2004. Morphological homoplasy, 1215 life history evolution, and historical biogeography of plethodontid salamanders 1216 inferred from complete mitochondrial genomes. Proc Natl Acad Sci USA 101:13820$1217 \quad 13825$.

1218 Noble GK. 1931. The Biology of the Amphibia. New York: McGraw-Hill. p 577.

1219 Noble GK, Brady MK. 1930. The courtship of the plethodontid salamanders. Copeia $1220 \quad 1930: 52-54$.

1221 Noble GK, Pope SH. 1929. The modification of the cloaca and teeth of the adult 1222 salamander, Desmognathus, by testicular transplants and by castration. J Exp Biol $1223 \quad 6: 401-411$.

1224 Parra-Olea G, Wake DB. 2001. Extreme morphological and ecological homoplasy in 1225 tropical salamanders. Proc Natl Acad Sci USA 98:7888-7891.

1226 Rasband WS. 2008. ImageJ. Bethesda, Maryland: U. S. National Institutes of Health. $1227 \quad \underline{\text { http://rsb.info.nih.gov/ij/ }}$

1228 Roth G. 1976. Experimental analysis of the prey catching behavior of Hydromantes italicus 1229 Dunn (Amphibia, Plethodontidae). J Comp Physiol A 109:47-58.

1230 Roth G. 1987. Visual Behavior in Salamanders. Berlin: Springer-Verlag.

1231 Roth G, Wake DB. 1985. Trends in the functional morphology and sensorimotor control of 1232 feeding behavior in salamanders: an example of the role of internal dynamics in 1233 evolution. Acta Biotheoretica 34:175-192. 
1234 Schwenk K, Wake DB. 1993. Prey processing in Leurognathus marmoratus and the 1235 evolution of form and function in desmognathine salamanders (Plethodontidae). Biol $1236 \quad J$ Linn Soc 49:141-162.

1237 Sessions SK, Stöck M, Vieites DR, Quarles R, Min MS, Wake DB. 2008. Cytogenetic 1238 analysis of the Asian plethodontid salamander, Karsenia koreana: Evidence for 1239 karyotypic conservation, chromosome repatterning, and genome size evolution. $1240 \quad$ Chromosome Res 16:563-574.

1241 Staub NL. 1993. Intraespecific agonistic behavior of the salamander Aneides flavipunctatus 1242 (Amphibia: Plethodontidae) with comparisons to other species. Herpetologica $1243 \quad 49: 271-282$.

1244 van der Meijden A, Chiari Y, Mucedda M, Carranza S, Corti C, Veith M. 2009.

1245 Phylogenetic relationships of Sardinian cave salamanders, genus Hydromantes, based 1246 on mitochondrial and nuclear DNA sequence data. Mol Phylogen Evol 51:399-404.

1247 Vieites DR, Min MS, Wake DB. 2007. Rapid diversification and dispersal during periods 1248 of global warming by plethodontid salamanders. Proc Natl Acad Sci USA $1249 \quad$ 104:19903-19907.

1250 Vieites DR, Zhang P, Wake DB. 2009. Salamanders (Caudata). In: Hedges SB, Kumar S, 1251 editors. The Timetree of Life. Oxford: Oxford University Press. p 365-368.

1252 Wake DB. 1963. Comparative osteology of the plethodontid salamander genus Aneides. J $1253 \quad$ Morphol 113:77-118.

1254 Wake DB. 1966. Comparative osteology and evolution of the lungless salamanders, family 1255 Plethodontidae. Mem South Cal Acad Sci 4:1-111. 
1256 Wake DB. 1987. Adaptive radiation of salamanders in Middle American cloud forests. Ann $1257 \quad$ Missouri Bot Gard 74:242-264.

1258 Wake DB. 1991. Homoplasy: the result of natural selection, or evidence of design 1259 limitations? Am Nat 138:543-567.

1260 Wake DB, Deban SM. 2000. Terrestrial feeding in salamanders. In: Schwenk K, editor. 1261 Feeding: Form, Function, Phylogeny. San Diego: Academic Press. p 95-116.

1262 Wake DB, Hanken J. 1996. Direct development in the lungless salamanders: what are the 1263 consequences for developmental biology, evolution and phylogenesis? Int J Dev Biol $1264 \quad 40: 859-869$.

1265 Wake DB, Larson A. 1987. Multidimensional analysis of an evolving lineage. Science $1266 \quad 238: 42-48$.

1267 Wake DB, Roth G. 1989. The linkage between ontogeny and phylogeny in the evolution of 1268 complex systems. In: Wake DB, Roth G, editors. Complex Organismal Functions: 1269 Integration and Evolution in Vertebrates. New York: Jon Wiley \& Sons Ltd. p 361$1270 \quad 377$.

1271 Wake DB, Roth G, Wake MH. 1983. On the problem of stasis in organismal evolution. J 1272 Theor Biol 101:211-224.

1273 Wake DB, Salvador A, Alonso-Zarazaga MA. 2005. Taxonomy of the plethodontid 1274 salamander genus Hydromantes (Caudata: Plethodontidae). Amphibia-Reptilia $1275 \quad 26: 543-548$.

1276 Wake TA, Wake DB, Wake MH. 1983. The ossification sequence of Aneides lugubris, with 1277 comments on heterochrony. J Herpetol 17:10-22. 
1278 Wells KD. 2007. The Ecology \& Behavior of Amphibians. Chicago: University of Chicago $1279 \quad$ Press. xi +1148 p.

1280 Wiedersheim R. 1875. Salamandrina perspicillata und Geotriton fuscus. Versuch einer 1281 vergleichenden Anatomie der Salamandrinen. Ann Musc Civ Stor Nat Genova 7:1$1282 \quad 207,17$ pls.

1283 Wiens JJ, Bonett RM, Chippindale PT. 2005. Ontogeny discombulates phylogeny: 1284 paedomorphosis and higher-level salamander relationships. Syst Biol 564:91-105.

1285 Wilder I, Dunn ER. 1920. The correlation of lunglessness in salamanders with a mountain 1286 brook habitat. Copeia 1920:63-68.

1287 Wiltenmuth EB. 1996. Agonistic and sensory behaviour of the salamander Ensatina 1288 eschscholtzii during asymmetrical contests. Anim Behav 52:841-850.

1289 Wiltenmuth EB, Nishikawa KC. 1998. Geographical variation in agonistic behaviour in a 1290 ring species of salamander, Ensatina eschscholtzii. Anim Behav 55:1595-1606.

1291 Zhang P, Wake DB. 2009. Higher-level salamander relationships and divergence dates 1292 inferred from complete mitochondrial genomes. Mol Phylogen Evol 53: 492-508. 


\section{Legends:}

1294 Fig. 1. Phylogenetic relationships within Plethodontinae. The phylogenetic tree has been 1295 simplified from Vieites et al. (2007) and is based on nuclear DNA markers. Karsenia, the 1296 only Asiatic plethodontid, is sister to the species of Hydromantes, which occur in North 1297 America and Europe. The remaining plethodontine and hemydactyliine species are 1298 distributed in the New World from southern Canada to Bolivia.

1300 Fig. 2. General overview of the skull of Karsenia koreana and Hydromantes platycephalus 1301 in dorsal (A, B), lateral (C, D), and frontal (E, F) views, respectively (scale bars: $\mathbf{A}, \mathbf{C}, \mathbf{E}=$ $13022 \mathrm{~mm} ; \mathbf{B}, \mathbf{D}, \mathbf{F}=3 \mathrm{~mm})$.

1304 Fig. 3. Premaxillae, maxillae, and septomaxillae in K. koreana (left panels: A, C, E, G) and 1305 H. platycephalus (right panels: B, D, F, H). A and B: frontolateral view of the skulls. Note 1306 the articulation in K. koreana between the septomaxilla and the prefrontal, and between the 1307 premaxilla, maxilla and vomer (A), articulations absent in H. platycephalus (B); C: anterior 1308 (a), medial (m), and posterior (p) views of the premaxilla in K. koreana; D: anterior (a), 1309 medial (m), and posterior (p) views of the premaxilla in H. platycephalus; $\mathbf{E}$ and $\mathbf{G}$ : lateral 1310 and medial views of the maxilla in $K$. koreana, respectively; $\mathbf{F}$ and $\mathbf{H}$ : lateral and medial 1311 views of the maxilla in $H$. platycephalus, respectively; appm, alary process of the 1312 premaxilla; m, maxillae; $n$, nasal; nld, nasolacrimal duct; pdpm, pars dentalis of the 1313 premaxilla; pdm, pars dentalis of the maxilla; pf, prefrontal; pfm, pars facialis of the 1314 maxilla; pppm, pars palatina of the premaxilla; ppm, pars palatina of the maxilla; pm, 
1315 premaxilla; sm, septomaxilla; v, vomer (scale bars: A, C, E, G = $1 \mathrm{~mm} ; \mathbf{B}, \mathbf{D}, \mathbf{F}, \mathbf{H}=2$

$1316 \mathrm{~mm})$.

1318 Fig. 4. Dorsolateral views of the skulls of K. koreana (A) and H. platycephalus (B), 1319 showing the articulations between, nasals, prefrontals, frontals, and parietals. An enlarged 1320 dorsal view of the nasal and prefrontal is provided. Prefrontals have been consistently 1321 reported absent in Hydromantes. In the specimen scanned, however, a differentiated 1322 element is found between frontals and nasal (pf?) $(\mathbf{B})$. appm, alary process of the 1323 premaxilla; f, frontal; fpf, frontoparietal fontanelle; m, maxilla; n, nasal; nld, nasolacrimal 1324 duct; os, orbitosphenoid; p, parietal; pdm, pars dentalis of the maxilla; pdpm, pars dentalis 1325 of the premaxilla; pf, prefrontal; ps, parasphenoid; sm, septomaxilla (scale bars: $\mathbf{A}=1 \mathrm{~mm}$; $1326 \quad \mathbf{B}=2 \mathrm{~mm})$.

1328 Fig. 5. Vomers in K. koreana (left panels, A, C, E) and H. platycephalus (right panels, B, 1329 D, F). A and B: frontal sections, showing the dorsal surfaces of the vomers and their 1330 articulation with premaxillae, maxillae, parasphenoid and orbitosphenoids. C and D: dorsal 1331 (d) and ventral (v) view of the isolated right vomers. $\mathbf{E}$ and $\mathbf{F}$ : ventral view of the skulls, 1332 showing the ventral disposition of the vomers, and the two posterior vomerine dental 1333 patches, attached to the parasphenoid. appm, alary process of the premaxilla; c, choana; dr, 1334 dentigerous ridge; $m$, maxillae; $n$, nasal; nld, nasolacrimal duct; pdm, pars dentalis of the 1335 maxilla; pdpm, pars dentalis of the premaxilla; pf, prefrontal; v, vomer; vb, anterior 1336 vomerine body; vdp, vomerine dental patch (scale bars: $\mathbf{A}=1 \mathrm{~mm} ; \mathbf{B}=2 \mathrm{~mm} ; \mathbf{C}=0.5 \mathrm{~mm}$; $1337 \mathbf{D}=1 \mathrm{~mm} ; \mathbf{E}=1 \mathrm{~mm} ; \mathbf{F}=2 \mathrm{~mm})$. 
1339 Fig. 6. Braincase in K. koreana (A, B) and H. platycephalus (C, D). A and C: lateral view

1340 of the skulls, showing the orbitosphenoids and their contact and articulation with vomers,

1341 parasphenoid, frontals, and parietals. B and D: transverse section of the skulls, about level

1342 of the anterior end of the orbitosphenoids. The braincases in the two species are very

1343 different in shape. Note also the absence of contact between vomers and orbitosphenoids in

1344 H. platycephalus. f, frontal; foc, foramen oculomotorium; fom, foramen orbitonasale

1345 mediale; of, optic fenestra; os, orbitosphenoid; p, parietal; ps, parasphenoid; v, vomer

1346 (scale bars: $\mathbf{A}, \mathbf{B}=1 \mathrm{~mm} ; \mathbf{C}, \mathbf{D}=2 \mathrm{~mm}$ ).

1348 Fig. 7. Occipito-otic complex in K. koreana (A, C) and H. platycephalus $(\mathbf{B}, \mathbf{D})$. A and B:

1349 Dorsal view of the posterior part of the skull. Note the different articulations between

1350 exoccipitals and atlas vertebrae, which correspond to differences in the relative size of the

1351 tuberculum interglenoideum of the atlas in the two species. C and D: posterolateral view of

1352 the skull. Note the different shape of the stylus of the pars media plectri. cr, crest; ex,

1353 exoccipital; fo, fenestra ovalis; oc, otic capsule; occ, occipital condyle; p, parietal; pmp,

1354 pars media plectri; st, stylus of the pars media plectri; ti, tuberculum integlenoideum (scale

1355 bars: $\mathbf{A}, \mathbf{C}=1 \mathrm{~mm} ; \mathbf{B}, \mathbf{D}=2 \mathrm{~mm}$ ).

1356

1357 Fig. 8. Anterior (a), lateral (l), posterior (p), and medial (m) views of the right squamosal

1358 and the quadrate, the only ossified element in the suspensorium, in K. koreana (A) and $H$.

1359 platycephalus $(\mathbf{B})$. The medial view (m) corresponds to a sagittal section at the level of the

1360 articulation between the otic capsule and the squamosal. Note the different articulation 
1361 between quadrate and articular in the two species. art, articular; den, dentary; prart,

1362 prearticular; oc, otic capsules; qu, quadrate; sq, squamosal; st, stylus of the pars media

1363 plectri (scale bars: $\mathbf{A}=0.5 \mathrm{~mm} ; \mathbf{B}=1 \mathrm{~mm})$.

1364

1365 Fig. 9. Lateral (1), medial (m), and dorsal (d) views of the right lower jaw in K. koreana (A)

1366 and $H$. platycephalus $(\mathbf{B})$. The posterior end of the mandible is not so robust in $H$.

1367 platycephalus. The coronoid process of the prearticular is less developed and the articular

1368 does not ossify. art, articular; cor, coronoid process of the prearticular; den, dentary; prart,

1369 prearticular; rid, ridge; sym, mandibular symphysis (scale bars: $\mathbf{A}=1 \mathrm{~mm} ; \mathbf{B}=2 \mathrm{~mm}$ ).

1370

1371 Fig. 10. Ventral views of the hyobranchial apparatus in Karsenia koreana (A),

1372 Hydromantes platycephalus (B), Desmognathus monticola (C), Plethodon neomexicanus

1373 (D), and Ensatina eschscholtzii (E). Hyobranchial parts are largely cartilaginous, with the 1374 exception of the central portion of the basibranchial in K. koreana and the urohyal in all

1375 species except $H$. platycephalus, which lacks it. Ossified segments are shown in dark grey.

1376 B, C, D, and E have been modified from Deban and Wake (2000). bb, basibranchial; cbI,

1377 ceratobranchial I; cbII, ceratobranchial II; ch, ceratohyal; eb, epibranchial; r, radial; uh, 1378 urohyal (scale bars $=5 \mathrm{~mm})$. 


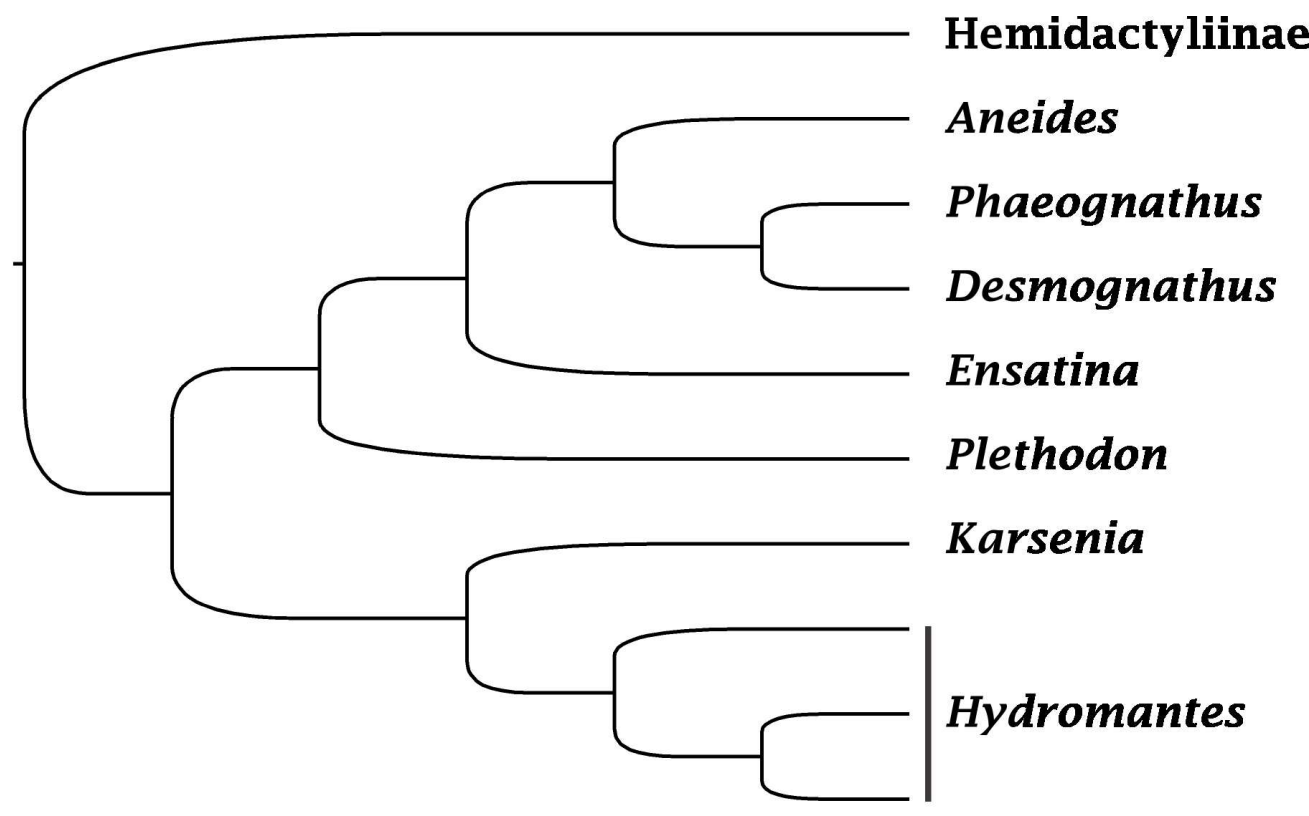

$76 \times 47 m m(600 \times 600$ DPI $)$ 


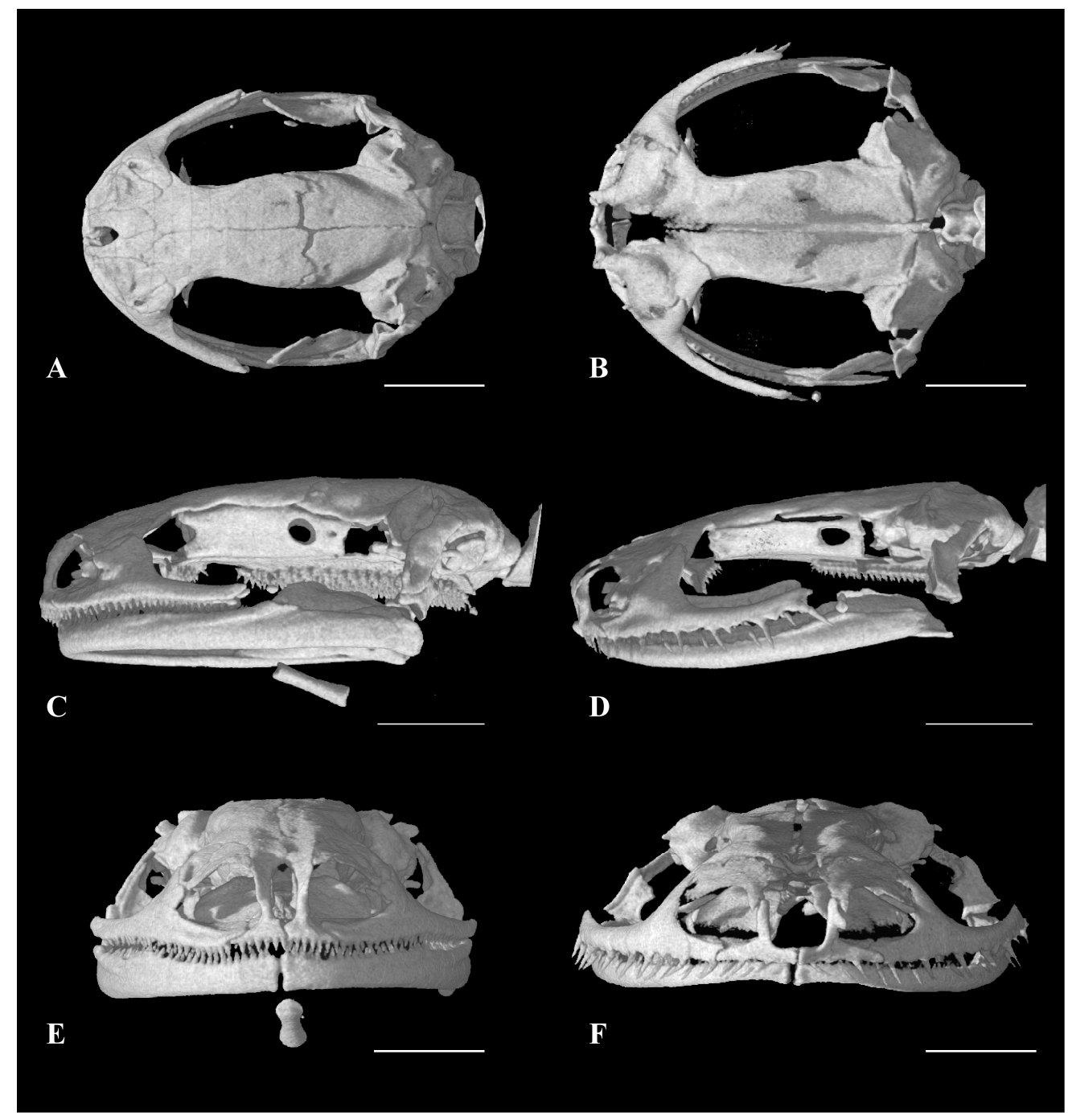

$172 \times 182 \mathrm{~mm}(600 \times 600 \mathrm{DPI})$ 


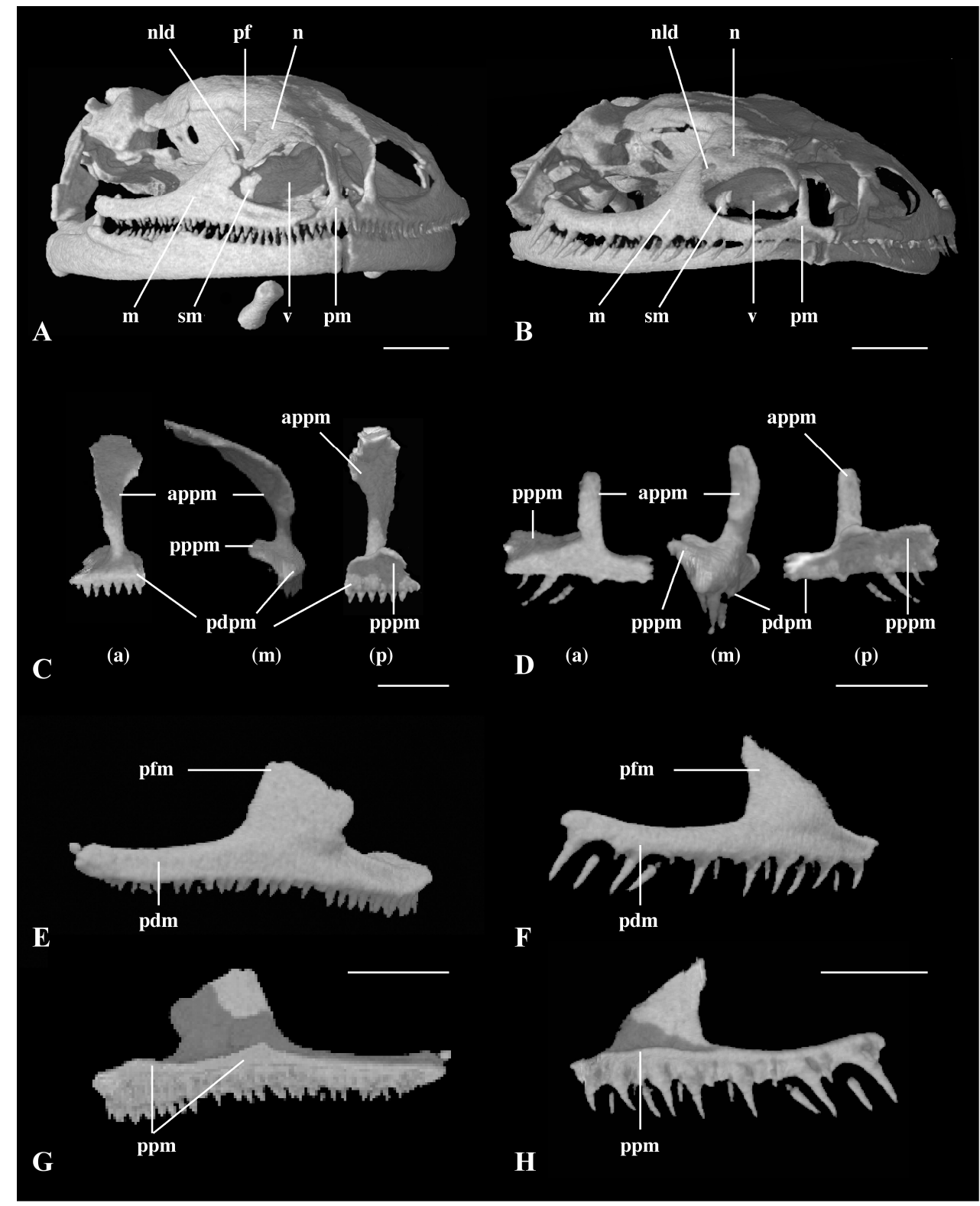

$167 \times 208 \mathrm{~mm}(600 \times 600 \mathrm{DPI})$ 


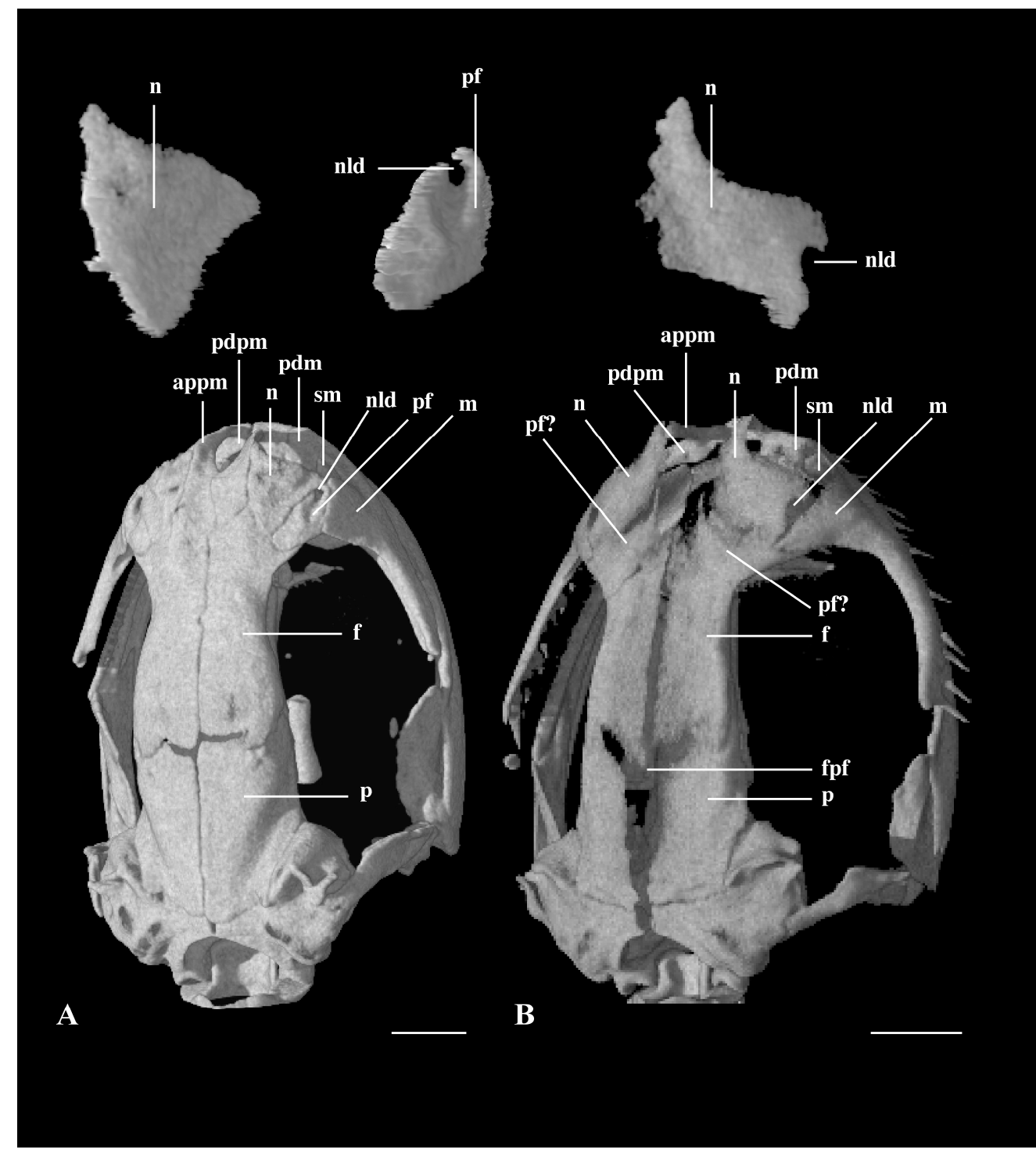

$159 \times 178 m m(600 \times 600$ DPI $)$ 


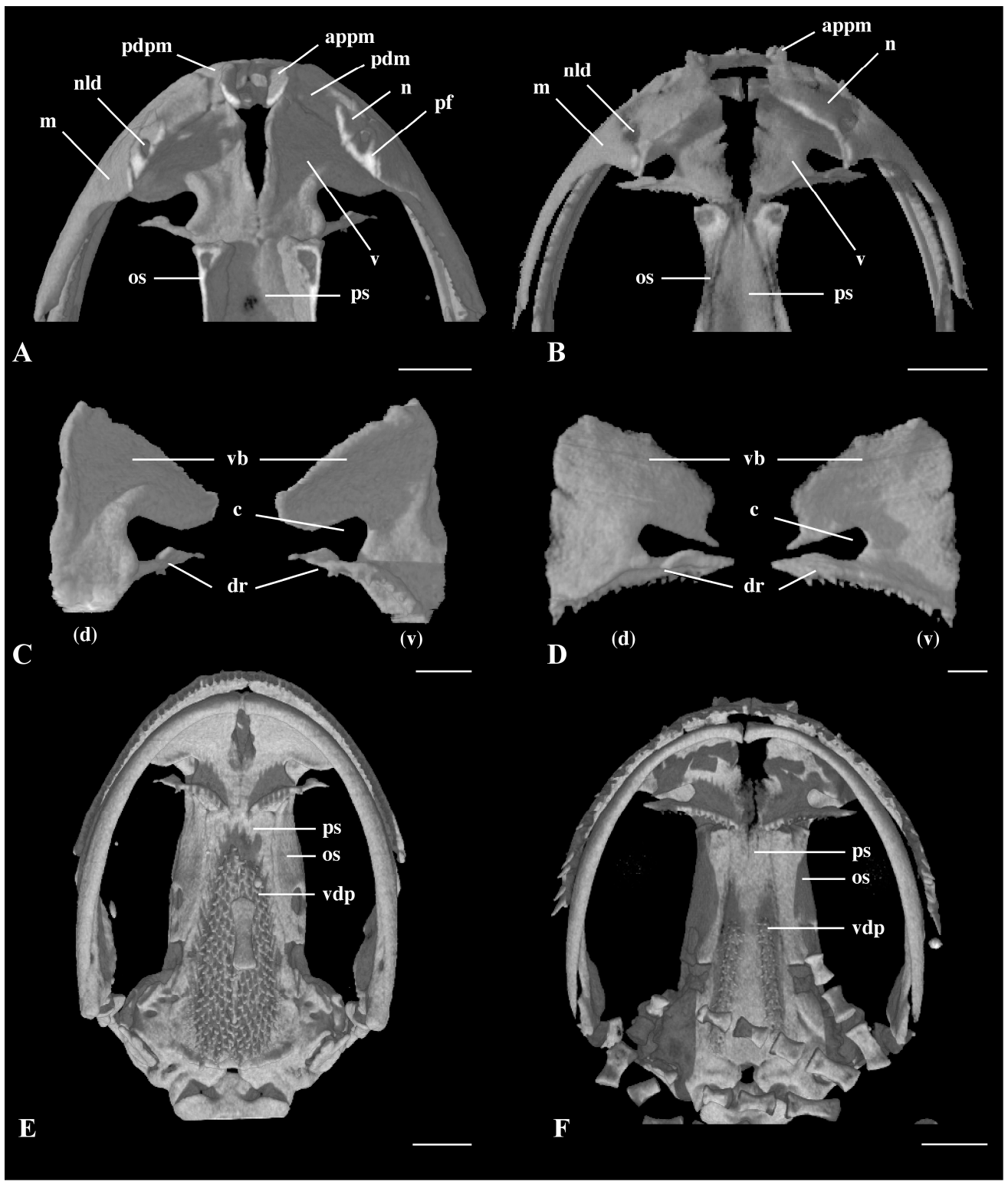

$172 \times 203 \mathrm{~mm}(600 \times 600 \mathrm{DPI})$

John Wiley \& Sons 

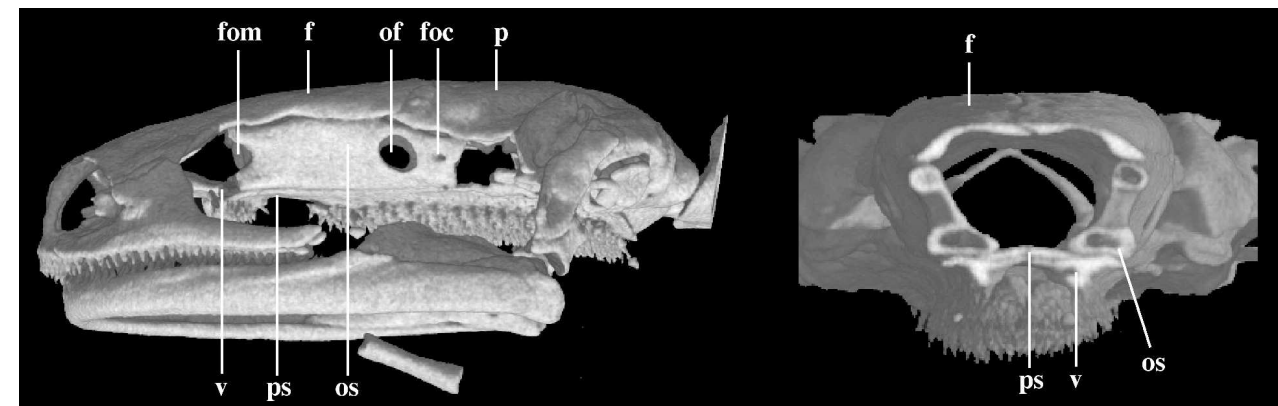

A

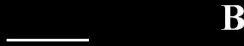

B
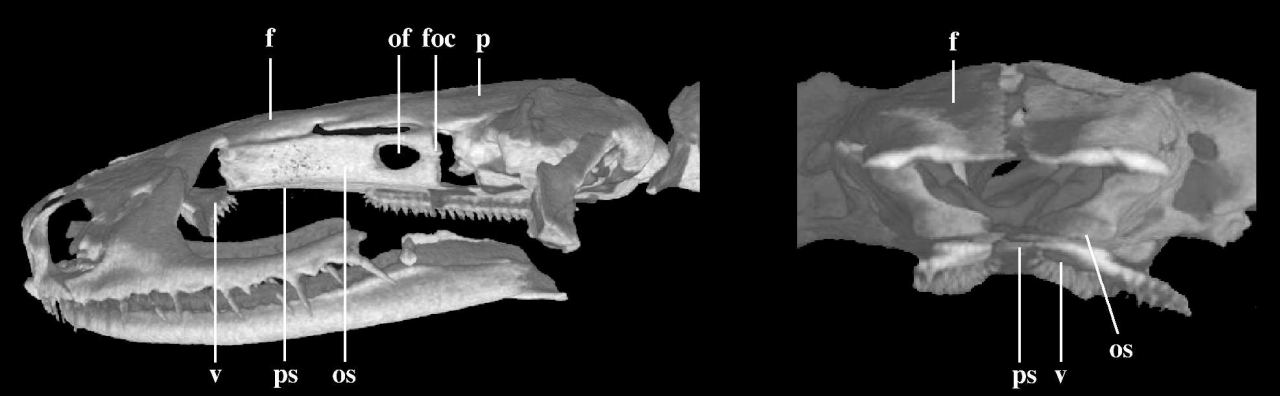

C

D

$170 \times 123 \mathrm{~mm}(600 \times 600 \mathrm{DPI})$ 


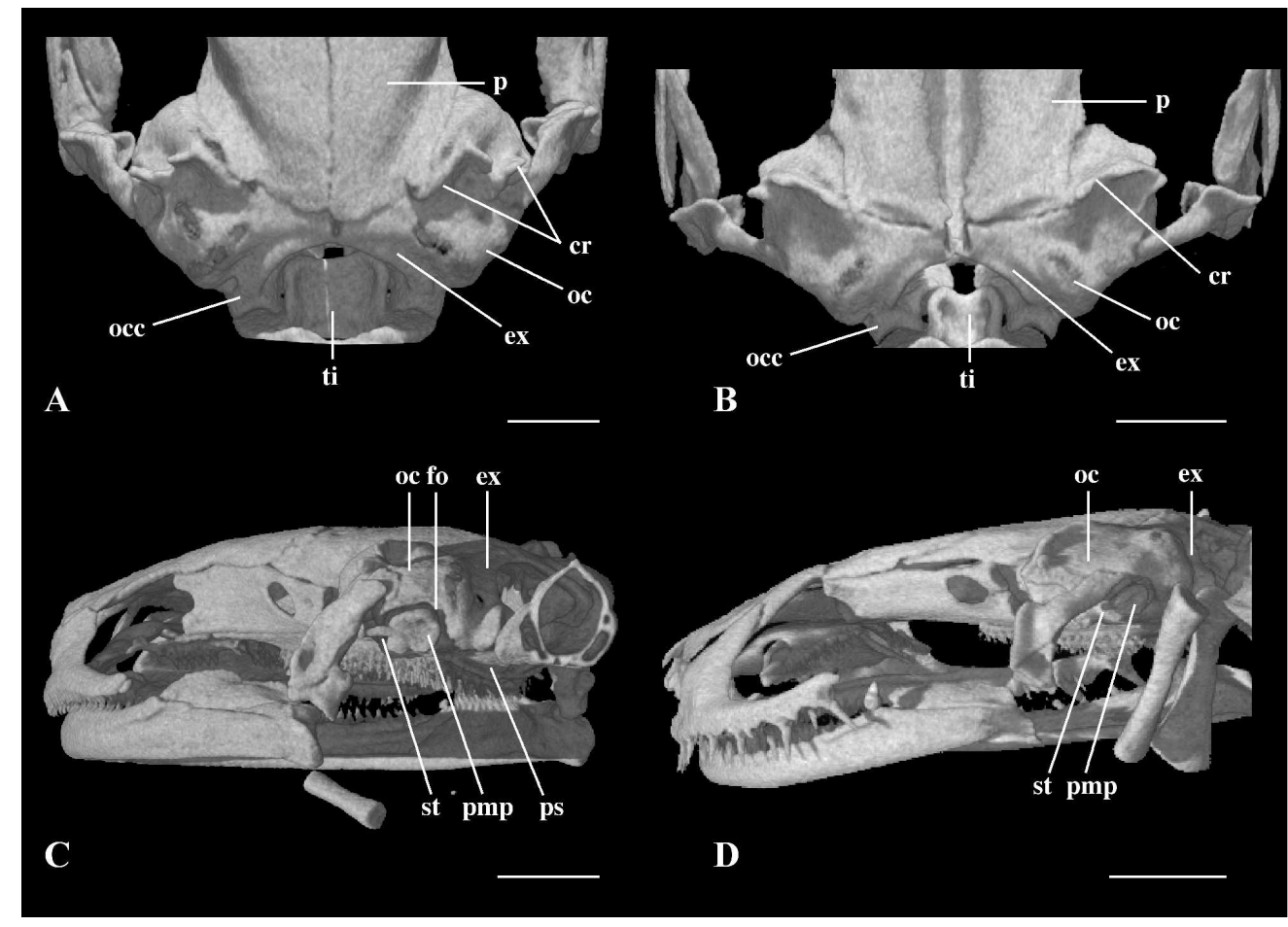

$169 \times 121 \mathrm{~mm}(600 \times 600 \mathrm{DPI})$ 


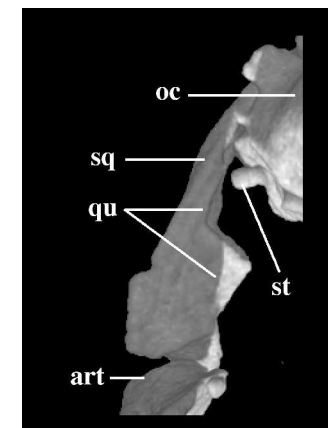

(a)

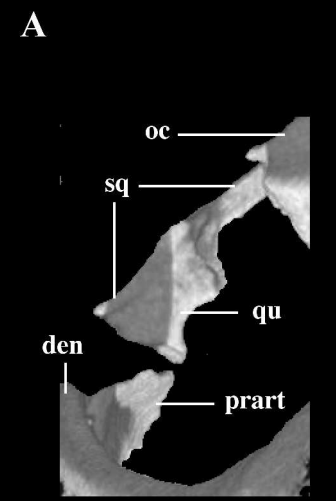

B

(a)

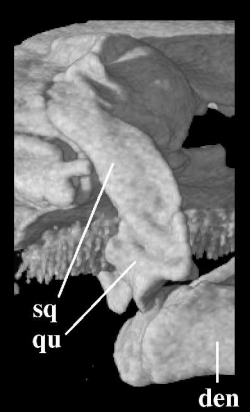

(I)

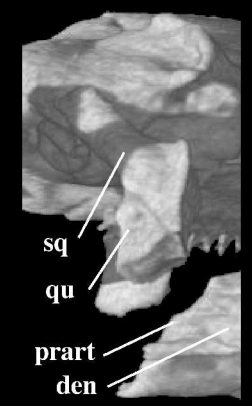

(I)

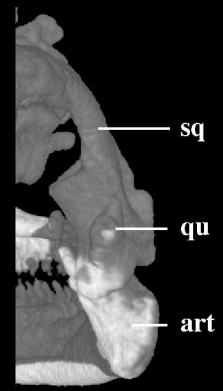

(p)

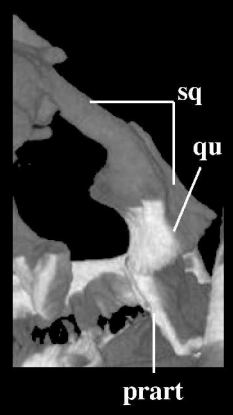

(p)



(m)



$172 \times 141 \mathrm{~mm}(600 \times 600 \mathrm{DPI})$ 


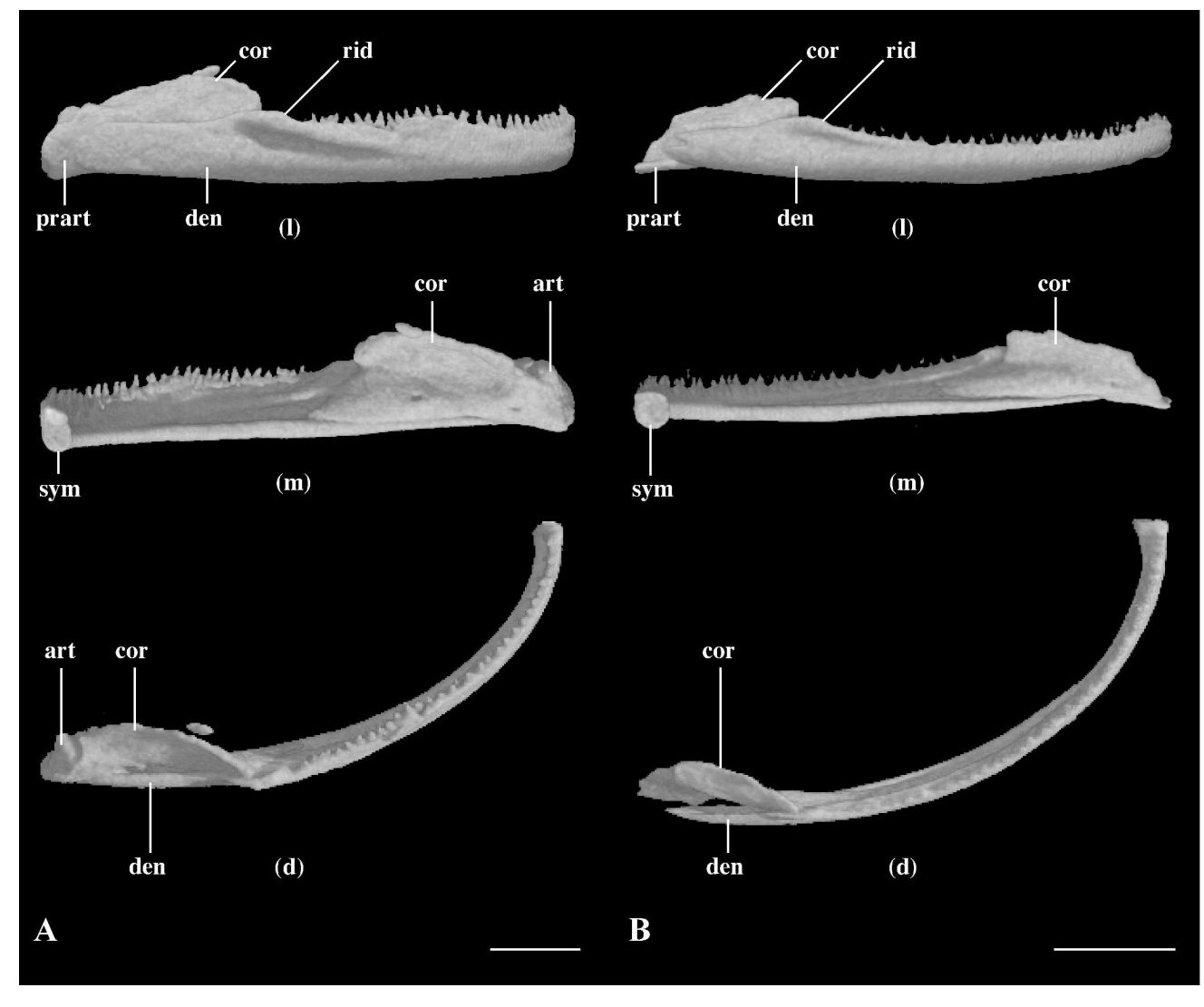

$172 \times 142 \mathrm{~mm}(600 \times 600 \mathrm{DPI})$

John Wiley \& Sons 


1
2
3
4
5
6
7
8
9
10
11
12
13
14
15
16
17
18
19
20
21
22
23
24
25
26
27
28
29
30
31
32
33
34
35
36
37
38
39
40
41
42
43
44
45
46
47
48
49
50
51
52
53
54
55
56
57
58
60
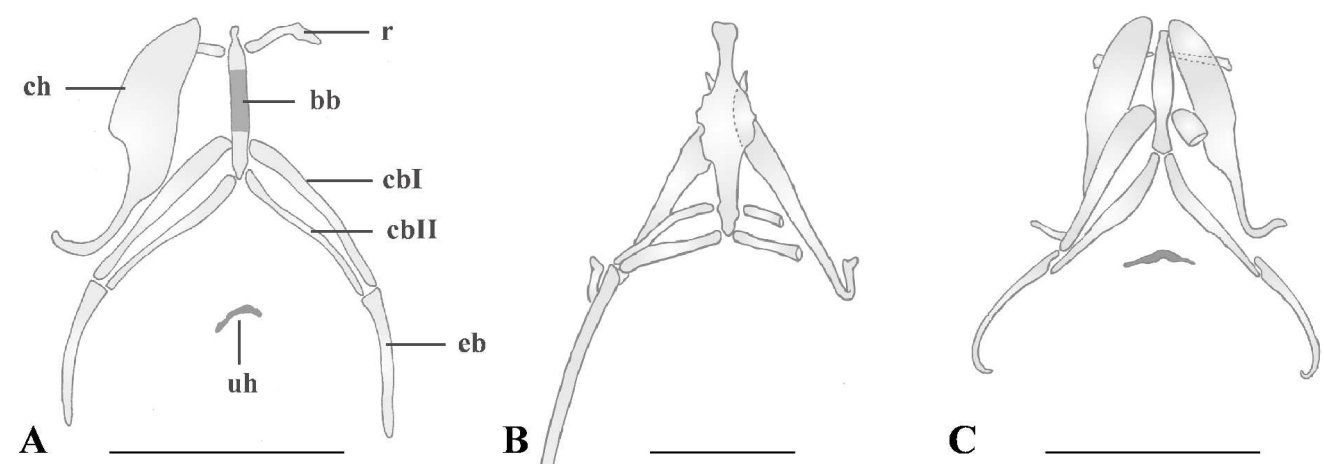

A

B

C

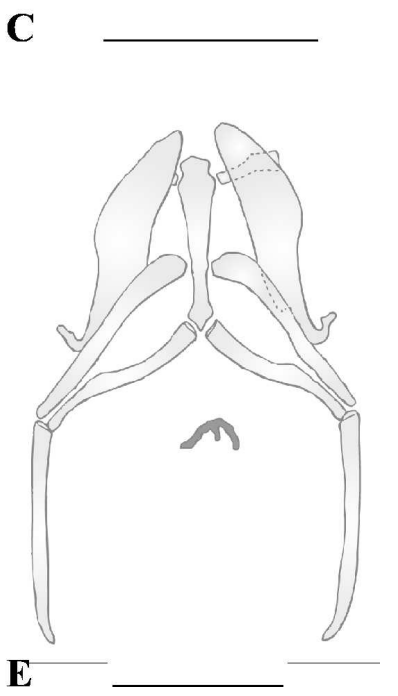

$158 \times 132 \mathrm{~mm}(600 \times 600 \mathrm{DPI})$
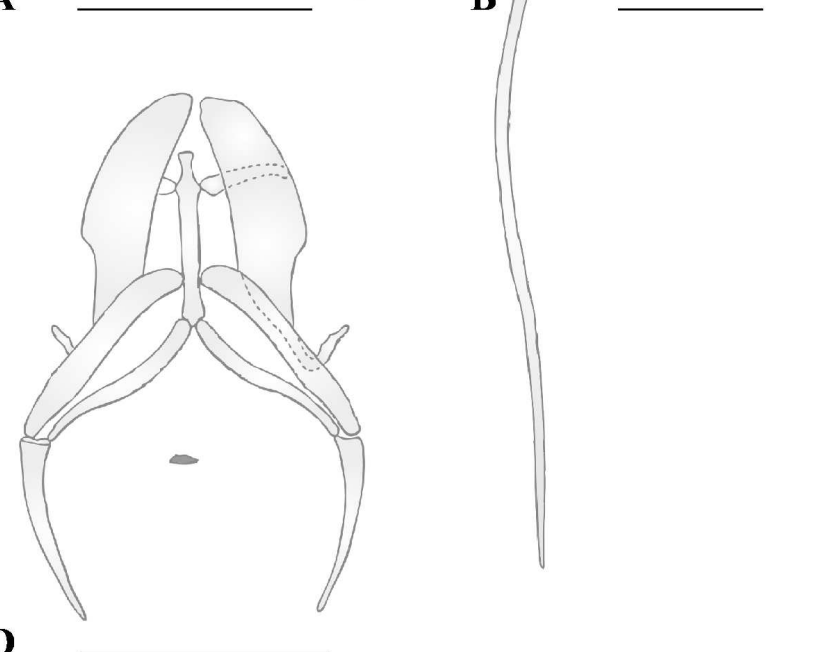

$\mathbf{E}$

John Wiley \& Sons 